\title{
Designing monographs for Rosmarinus officinalis L. and Lavan- dula angustifolia L.: Two Lebanese species with significant me- dicinal potentials
}

\author{
Mariam Koleilat, Karim Raafat*, Abdalla El-Lakany, Maha Aboul-Ela
}

Mariam Koleilat, Karim Raafat*, Abdalla El-Lakany, Maha AboulEla

Department of Pharmaceutical Sciences, Faculty of Pharmacy, Beirut Arab University, 115020 Beirut, LEBANON.

Correspondence

Dr. Karim Raafat

Department of Pharmaceutical Sciences, Faculty of Pharmacy, Beirut Arab University 115020 Beirut, LEBANON.

Phone number: 9611300110

E-mail: k.raafat@bau.edu.lb, karim. raafat@yahoo.com

\section{History}

- Submission Date: 12-12-2016;

- Review completed: 05-01-2017;

- Accepted Date: 03-02-2017.

DOI : 10.5530/pj.2017.4.75

Article Available online

http://www.phcogj.com/v9/i4

\section{Copyright}

(C) 2016 Phcog.Net. This is an openaccess article distributed under the terms of the Creative Commons Attribution 4.0 International license.

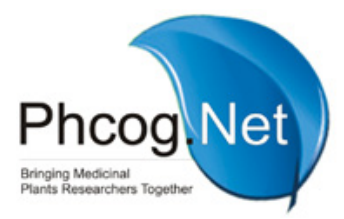

\begin{abstract}
Introduction: The world health organization recommends validating medicinal plants to ensure safety and efficacy. Lavandula is valued for the production of essential oil used in aromatherapy. Rosmarinus is known for its folk use as anti-oxidant and antidiabetic. This study aims to design monographs for Rosmarinus officinalis (Linn.) and Lavandula angustifolia (Linn.) cultivated, in conditions similar to their natural habitat, at Beirut Arab University botanical garden. Also screening the antioxidant activity of both plants, and assessing the antidiabetic effect of R. officinalis (Linn.). Methods: macroscopic and microscopic examination, hydrodistillation to obtain essential oils (EOs), thin layer chromatography, Gas chromatography-Mass spectrometry, and physiochemical properties of the EOs were determined. The antioxidant effect of the EOs is determined by DPPH assay. The antidiabetic effect of Rosemary EO is investigated using alloxan-induced diabetic mice. Results: the qualities of studied species are in agreement with the standards described in WHO monographs and in the British pharmacopeia. Composition of the EO produced from either Rosemary (REO) or Lavender (LEO) collected at different months showed differences. The EO of both showed significant antioxidant effects in DPPH assay $(p<0.05)$. In vivo investigation of the antidiabetic effect of REO showed a significant antidiabetic effect in diabetic mouse model $(p<0.05)$. Conclusion: both plant species and their EOs fulfilled most of standards specified by the British Pharmacopeia 2013. Rosemary collected in April (Spring) showed the best antioxidant activity. Lavender collected in September (Early Fall) showed the best antioxidant activity. REO revealed significant lowering in blood glucose level at the dose of $110 \mathrm{mg} / \mathrm{kg}$.

Key words: Prismatic crystals of Calcium oxalate, Glandular trichome, Rosmarinic acid, Optical rotation, Refractive index.
\end{abstract}

\section{INTRODUCTION}

Worldwide use of herbal medicine has been notably increasing in the last few decades. ${ }^{1,2}$ In developing countries, many people have been utilizing alternative medicine to meet their essential health care requirements. On the other hand, developed countries had an increasing interest in medicinal herbs. ${ }^{2}$ Among plant species that have been used for long as medicinal herbs, few have been evaluated scientifically for their various therapeutic applications in folk medicine. ${ }^{3}$ Very limited information has been presented regarding the efficacy and safety of medicinal herbs, their extracts or active ingredients and formulations containing them. ${ }^{3,4}$ The most important issue about herbal medicine is that their market is inadequately regulated. Most often, registration of and control over herbal products are lacking. ${ }^{3}$ Therefore, assuring quality, safety and efficacy is a global issue. Both the general consumer and the health care provider need updated and reliable data about traditionally used medicines. ${ }^{3,5}$ Monographs provide assistance in the harmless and efficient use of herbal medicines. ${ }^{3}$

Rosmarinus officinalis (Linn.) (Rosemary) (Lamiaceae) also known as garden rosemary, hasalban, iklil el jabal and romarin. ${ }^{6}$ It is a branched, bushy, evergreen sub-shrub that attains a height of 1-2 meters. It grows wildly in many regions of the world mainly in the Mediterranean region. ${ }^{6-9}$ It has been reported to include about 20 different varieties that can be distinguished based on morphological features such as the leaf dimensions and the flower's calyx and corolla. ${ }^{10}$ Rosemary leaves are linear, leathery and dark green. The flowers are very small and are light blue. Both flowers and leaves are characterized by a strong aromatic odor due to the volatile oil that accumulates in glandular trichomes that are of the capitate and labiaceous type. ${ }^{9}$ In Lebanon, Rosemary has been described as one of 28 medicinal plant species considered to be the most important. ${ }^{11}$ Reported folk medicine indications of rosemary include its use in inflammation and wound healing, headache, arthritis, gout, abdominal pain and intestinal spasm, water retention, indigestion and depression. ${ }^{9,12,13}$ It could be used fresh, dry or distilled to obtain the essential oil (EO) ${ }^{8,14}$ Rosemary has been reported to be one of the aromatic plants having high antioxidant activity ${ }^{7}$ The EO and extracts of Rosemary have been tested 
for their antioxidant potentials. ${ }^{7,15}$ The antioxidant activity of the EO of Rosemary was linked to its main components ${ }^{16}$ which vary with seasonal variations. ${ }^{17}$ Besides its antioxidant potential, the extracts of Rosemary have been studied before for their antidiabetic effect. ${ }^{8}$ However, very few studies reported the antidiabetic effect of Rosemary EO. ${ }^{18}$ Lavandula angustifolia (Linn) (Lavender) (Lamiaceae), known as English lavender, true lavender and khuzama, is also one of the most important herbs grown in Lebanon ${ }^{19}$ Traditionally, the EO of Lavender was used as an antiseptic for burns and wounds. ${ }^{20}$ Several biological activities of this species have been reported such as its antimicrobial ${ }^{21}$ and antimutagenic properties. ${ }^{20}$ Similar to Rosemary, the antioxidant potential of Lavender essential oil (LEO) has been reported before and it has been linked to the oil's composition, which varied with seasonal variations. ${ }^{22}$ Such variations in composition and subsequently on biological effect caused by seasonality should be screened in order to obtain an EO with standard quality. ${ }^{17}$

This study was conducted in order to assure the quality and safety of herbal products before being available to the public, pharmacognostic screening on Rosmarinus officinalis and Lavandula angustifolia (Linn.) grown in Lebanon was conducted. Moreover, taking into consideration that there are no enough data about seasonal influence on the chemical composition of EO obtained from Lebanese plants, it was of interest to evaluate the effects of seasonal variation on composition and antioxidant activities of REO and LEO. In addition, the antidiabetic effect of REO was explored since available information in this regards were very limited. Therefore, this study will serve to complete the profile of the chosen genera in comparison with the previous literature about both genera Rosmarinus and Lavandula worldwide.

\section{MATERIALS AND METHODS}

\section{Chemicals}

Alloxan monohydrate, sodium chloride ( $\mathrm{NaCl}), 2,2$ '- diphenyl-1-picrylhydrazyl (DPPH), ascorbic acid (AA), glucose, bornyl acetate (95\%), limonene, linalool (97\%), borneol, 1,8-cineole, and linalyl acetate (Sigma, Aldrich). All chemicals used were of analytical grade.

\section{Plant materials}

Aerial parts of Rosmarinus officinalis (Linn.) (Rosemary) and Lavandula angustifolia (Linn.) (Lavender) were obtained from the Botanical Garden, Research Center for Environment and Development, Beirut Arab University, Bekaa. R. officinalis (Linn.) was identified by Dr. N. Arnold (USJ, Lebanon). L. angustfolia (Linn.) was identified according to its botanical characteristics presented in the BP 2013. Voucher sample were deposited at the faculty herbarium. Five samples of $R$. officinalis (Linn.) were obtained during the years 2013 and 2014. Sample 1: August 2013 (R-AG); sample 2: March 2014 (R-MR); sample 3: April 2014 (R-AP); sample 4: June 2014 (R-JN); sample 5: September 2014 (R-SP). Two samples of Lavandula angustiflolia were obtained during the years 2014 and 2015. Sample 1: September 2014 (L-SP); sample 2: July 2015 (L-JL).

\section{Microscopic examination}

Dried plant material was first reduced into fine powder flowed by mounting the powder in chloral hydrate solution $(4 \mathrm{mg} / \mathrm{ml})$. The prepared mount was then examined under a light microscope (Optika B150, Italy). ${ }^{23}$

\section{Assay of the plant material for the essential oil yield}

An amount of $30 \mathrm{~g}$ of fresh plant material (leaves of Rosemary and flowers of Lavender) was subjected to hydro-distillation using a Clevengertype apparatus for $4 \mathrm{~h}$. Three hundred $\mathrm{ml}$ of distilled water were used as the distillation liquid. ${ }^{23}$ The liberated oil was collected after drying over anhydrous sodium sulphate and stored in a freezer at $\left(4-5^{\circ} \mathrm{C}\right)$ until used. ${ }^{24}$ The yield of the obtained Rosemary essential oil (REO) and Lavender essential oil (LEO) was calculated relative to the weight of the sample. Figures 12,13,14,15 and 16 represent calibration curves for REO yield. Figures 18 and 19 represent calibration curves for LEO yield.

\section{Spectrophotometric assay of the plant material} (Rosemary samples) for the total hydroxycinnamic acid derivatives

A volume of $80 \mathrm{ml}$ of $50 \%$ ethanol were added to $0.2 \mathrm{~g}$ of the powdered drug and boiled in water bath (BUCHI ${ }^{\circ}$ B-491) under a reflux condenser for $30 \mathrm{~min}$. After filtration, the residue was rinsed with $10 \mathrm{ml}$ of $50 \%$ ethanol. The filtrate and the rinsing were combined in a volumetric flask and diluted to $100 \mathrm{ml}$ with $50 \%$ alcohol. The test solution was prepared by taking $1 \mathrm{ml}$ of this stock solution and adding to it $2 \mathrm{ml}$ of $0.5 \mathrm{M} \mathrm{HCl}$, $2 \mathrm{ml}$ of a solution prepared by dissolving $10 \mathrm{~g}$ of sodium nitrite and $10 \mathrm{~g}$ of sodium molybdate in $100 \mathrm{ml}$ of water, $2 \mathrm{ml}$ of dilute $\mathrm{NaOH}$ solution and diluting to $10 \mathrm{ml}$ with water and mixing. Compensation solution was prepared by diluting $1 \mathrm{ml}$ of the stock solution to $10.0 \mathrm{ml}$ with water. Absorbance of the test solution was measured immediately at $\lambda=505 \mathrm{~nm}$. The percentage content of total hydroxycinnamic derivatives, expressed as rosmarinic acid, was calculated from the expression: $\frac{A \times 2.5}{m}$, where $A=$ absorbance of the test solution at $505 \mathrm{~nm}$ and $m=$ mass of the substance to be examined in grams. The specific absorbance ${ }^{\mathrm{A}_{1 \mathrm{~cm}}^{1 \%}}$ of rosmarinic acid $=400 \cdot{ }^{23}$ Calibration curve for Rosmarinic acid is available (figure 17).

\section{Inspection of plant material for foreign matter and moisture contents}

$100 \mathrm{~g}$ of each sample was spread out in a thin layer. Examining for foreign matter was done by inspection with the unaided eye. The foreign matter was separated and weighed to calculate its percentage. ${ }^{23}$

\section{Moisture content in the plant material}

The moisture content in $1 \mathrm{~g}$ of dried powdered Rosemary leaves or Laveneder flowers was determined using an $\mathrm{OHAUS}^{\circledR}$ MB 200 moisture balance. A mass of $1 \mathrm{~g}$ of the powdered plant material was spread in a thin layer in the crucible of the moisture balance apparatus. Temperature was set at $100^{\circ} \mathrm{C}$. Plant material was kept under this temperature until the moisture content attained a constant value (30-40 minutes).$^{25}$

\section{Chromatographic analysis of the essential oil}

\section{Thin layer chromatography (TLC)}

The test solution for each oil was prepared by dissolving $50 \mu \mathrm{l}$ of the oil in $1 \mathrm{ml}$ of toluene. The reference solution for REO was prepared by dissolving $5 \mathrm{mg}$ of borneol, $5 \mathrm{mg}$ of bornyl acetate and $10 \mu \mathrm{l}$ of 1,8-cineole in $1 \mathrm{ml}$ of toluene. The reference solution for LEO was prepared by dissolving $10 \mu \mathrm{l}$ of linalol, $10 \mu \mathrm{l}$ of 1,8-cineole and $10 \mu \mathrm{l}$ of linalyl acetate in $1 \mathrm{ml}$ of toluene. The test and reference solutions were applied as spots on TLC silica gel plate. The spots were allowed to develop over a path of 15 $\mathrm{cm}$ using ethyl acetate, toluene $(5: 95 \mathrm{~V} / \mathrm{V})$ as mobile phase. The plate was allowed to dry in air. The plate was then sprayed with vanillin reagent for (REO), anisaldehyde reagent (LEO) and heated at $105^{\circ} \mathrm{C}$ for $10 \mathrm{~min}$. This was followed by examining the plate immediately in daylight. ${ }^{23}$

\section{Gas Chromatography-Mass Spectrometry (GC-MS)}

GC-MS analyses were performed using a GC (Agilent 6890N) coupled with Mass spectrometer (5975 B), equipped with a split/splitless injector. Separation and quantitation were performed using a DB-WAX column, $30 \mathrm{~m} \times 0.252 \mathrm{~mm}$ ID, with a film thickness $0.25 \mu \mathrm{m}$ (J \& W Scientific Inc., Folsom, California, USA). For REO, the GC oven temperature pro- 
gram used was as follows: initial temperature $50^{\circ} \mathrm{C}$, held for $10 \mathrm{~min}$ then ramped at $2^{\circ} \mathrm{C} / \mathrm{min}$ to $200^{\circ} \mathrm{C}$, and held isothermally for $25 \mathrm{~min}$. Helium was used as the carrier gas at a flow rate of $1 \mathrm{ml} / \mathrm{min}$. The detector temperature was set at $250^{\circ} \mathrm{C}$ and the injector block temperature at $200^{\circ} \mathrm{C}$. For LEO, the GC oven temperature program used was as follows: initial temperature $70^{\circ} \mathrm{C}$, held isothermally for $15 \mathrm{~min}$ then ramped at $2^{\circ} \mathrm{C} / \mathrm{min}$ to $180^{\circ} \mathrm{C}$. Helium was used as the carrier gas at a flow rate of $1.5 \mathrm{ml} / \mathrm{min}$. The detector temperature was set at $220^{\circ} \mathrm{C}$ and the injector block temperature at $220^{\circ} \mathrm{C}$. Samples were prepared by diluting the oil in hexane with a dilution ratio of 2:100. The volume injected sample was $1 \mu \mathrm{l}$ of the diluted oil, split mode injection technique (1:50). ${ }^{23}$ The mass spectra were recorded over a range of 50-550 amu at 0.345. Constituents of REO and LEO were identified by comparing recorded mass spectra with those stored in the spectrometer database (MS library-NIST05). The relative percentage amounts of separated compounds were calculated from total ion chromatogram by a computerized integrator.

\section{Physiochemical properties of the essential oil}

\section{Relative density of the oil}

The relative density ${ }^{\left({ }_{20}^{20}\right)}$ of each of REO and LEO was determined by first measuring the mass of $1 \mathrm{ml}$ of the oil at $20^{\circ} \mathrm{C}$. This way, the density $\left(\rho_{20}\right)$ which is the mass of a unit volume of the oil at $20^{\circ} \mathrm{C}$ expressed in $\left(\mathrm{g} \cdot \mathrm{cm}^{-3}\right)$ was obtained. $\rho_{20}{ }_{20}^{20}$ are related by the following equation: $d_{20}^{20}$ $=1.00180 \times \rho_{20}{ }^{23}$

\section{Refractive index of the oil}

The refractive indices of both REO and LEO were measured using a REF $123^{\circ}$ digital refractometer. Measurement was done at $20 \pm 0.2^{\circ} \mathrm{C}^{23}$

\section{Optical rotation of the oil}

The angle of rotation for each of REO and LEO was measured using a WZZ-2SS • digital automatic polarimeter. Solutions of REO and LEO were prepared in hexane in a concentration of $25 \mathrm{~g} / \mathrm{L}$. measurements were made at $20^{\circ} \mathrm{C}$ using $1 \mathrm{dm}$ tubes. The angle of rotation ${ }^{[\alpha]_{D}^{20}}$ was measured according to the following equation ${ }^{23}:[\alpha]_{D}^{20}=\frac{1000 \alpha}{l . c}$, where $c$ is the concentration $(\mathrm{g} / \mathrm{L}), \alpha=$ angle of rotation in degrees read at $20, l=$ length of the polarimeter tube in $(\mathrm{dm}){ }^{23}$

\section{Acid value of the oil}

$1 \mathrm{~g}$ of the oil was dissolved in $50 \mathrm{ml}$ of a mixture of equal volumes of ethanol (96\%) and light petroleum, previously neutralized with $0.1 \mathrm{M}$ sodium hydroxide, using $0.5 \mathrm{ml}$ of phenolphthalein solution as indicator. The dissolved oil was then titrated with $0.1 \mathrm{M}$ sodium hydroxide until the pink color persisted for at least 15 seconds. The acid value was then determined using the following equation: $I_{A}=\frac{5.610 n}{m}$, where $n=\mathrm{ml}$ of titrant and $\mathrm{m}=$ mass of the oil in grams. ${ }^{23}$

\section{Determination of the antioxidant activity of Rosmarinus officinalis (Linn.) and Lavandula angustifolia (Linn.) essential oils with the 2,2'- Diphenyl-1-picrylhydrazyl (DPPH) radical scavenging method}

The ability of the EOs to reduce DPPH radical was determined by the method previously reported. ${ }^{26}$ Briefly, methanolic solutions of the REO and of LEO at different concentrations $(2.5,5,10,15,20$ and $25 \mu \mathrm{l} / \mathrm{ml}$ for REO and 5, 10, 15, 20, 25 and $30 \mu \mathrm{l} / \mathrm{ml}$ for LEO) were prepared. $2 \mathrm{ml}$ of each solution were put into a cuvette, and $40 \mu \mathrm{l}$ of $4 \mathrm{mg} / \mathrm{ml}$ methanolic solution of DPPH were added. Measurement of absorbance, at $517 \mathrm{~nm}$, for each test solution was started immediately after DPPH addition. The absorbance was then determined at 0, 20, 40 and 60 minutes for all samples. Measurements were done using an OPTIMA spectrophotometer (OPTIMA, Japan). Methanol was used as blank with zero absorbance at the $517 \mathrm{~nm}$. DPPH radical without antioxidant, i.e. the vehicle, was used as a control. Ascorbic acid $0.2 \mathrm{mg} / \mathrm{ml}$ was used as a positive control. Percent scavenging of the DPPH radical by the different samples was calculated using this formula: \% SCAVENGING $=\left[\left(\mathrm{AC}_{(\mathrm{o})}-\mathrm{AA}_{(\mathrm{t})}\right) / \mathrm{AC}_{(\mathrm{o})}\right]$ $* 100$, where $\mathrm{AC}_{(\mathrm{o})}$ is the absorbance of the control at $\mathrm{t}=0 \mathrm{~min}$ and $\mathrm{AA}_{(\mathrm{t})}$ is the absorbance of the antioxidant at $\mathrm{t}=1 \mathrm{~h} .{ }^{26}$ Percent scavenging after 60 min was plotted against concentration, and a linear regression was applied to obtain the $\mathrm{IC}_{50}$ value.

\section{In vivo investigation of the antidiabetic effect of Rosmarinus officinalis (Linn.) essential oil}

\section{Animals}

Male Swiss-Webster mice, 12 to 16 weeks of age, were kept in adaptation environment for a period of 1 week prior to initiation of the experimental procedure. The adaptation environment was similar to the conditions previously described. ${ }^{8}$ The mice were kept in individual cages at room temperature of $22 \pm 1^{\circ} \mathrm{C}$ and a light/dark cycle of $12 \mathrm{hrs}$ each. The animals had free water access and were fed with standard pellets of proteins (20\%), fats (5\%) and multivitamins (1\%). Sixteen hrs prior to experimentation, feeding pellets were removed from the cages in order to make the mice fast. However, the free access to water was kept. Experimentation on animals and animal care were all done according to the regulations of the Lebanese Ministry of Higher Education and the animal experiment legislation and with the approval code (2016A-0035-P-M-112) of the Institutional Review Board of Beirut Arab University.

\section{Diabetes induction}

Diabetes was induced by alloxan. Alloxan is a cytotoxin that harms the pancreatic $\beta$-cells. This leads to loss of the ability of tissues to utilize glucose and hence animals become diabetic. Alloxination method was done as previously described. ${ }^{8,27,28}$ Briefly, alloxan was dissolved in sterile cold saline $(0.9 \%)$. It was given to mice at a dose of $180 \mathrm{mg} / \mathrm{kg}$ every $48-\mathrm{hr}$. This injection was given for three times. $72 \mathrm{hrs}$ after the last injection of alloxan, blood samples were obtained from mice tails to measure the fasting blood glucose (FBG) levels. Measurements were done using glucose strips meter (Accu-check Performa ${ }^{\mathrm{TM}}$ - Roche, USA). Mice with FBG levels greater than $200 \mathrm{mg} / \mathrm{dl}$ were considered to be diabetic and were used in the experiment.

\section{Acute effect of REO in alloxan induced diabetic mice}

Testing for the acute effect of REO was done as previously described. ${ }^{8} \mathrm{Di}$ abetic mice were grouped as follows: five groups with n=7/group. Group (I) was the control group and received the vehicle only which is $0.9 \%$ cold sterile saline. Group (II) received a reference hypoglycemic drug which is Glibenclamide. It is a sulfonylurea that is well known to produce its hypoglycemic effect by increasing the pancreatic release of insulin. ${ }^{27}$ Glibenclamide (GB), dissolved in DMSO was given at a dose of $5 \mathrm{mg} / \mathrm{kg}$, IP. REO, dissolved in the vehicle, was injected at the doses of 80,100 and $110 \mathrm{mg} / \mathrm{kg}$ IP to the mice of group (III, IV, and V), respectively. Blood samples were obtained from the mice tails before the injections and at the end of the first half, $2^{\text {nd }}$ and $6^{\text {th }}$ hr after injections. The concentration of glucose in blood samples was then measured.

\section{Subacute effect of REO in alloxan induced diabetic mice}

Testing the action of REO for longer period of treatment was also done as previously reported. ${ }^{27,28}$ Mice were grouped into normal control and diabetic animals. Group (I) (normal control mice, $n=7$ ) received only a vehicle IP for 7 days and served as control. The diabetic mice were divided into five groups (II-VI) of seven animals each. Group II received only the vehicle, $0.9 \%$ cold sterile saline IP for 7 days and served as diabetic control. Group III received GB as the reference drug $(5 \mathrm{mg} / \mathrm{kg}$, IP) dissolved in DMSO for 7 days (positive control). REO, dissolved a in 
vehicle, and was administered at the doses of 80,100 and $110 \mathrm{mg} / \mathrm{kg}$ IP to the animals of group IV, V and VI, respectively. Blood samples were collected from the tail on the $1^{\text {st }}, 3^{\text {rd }}, 5^{\text {th }}$, and $8^{\text {th }}$ days after each treatment. Blood glucose levels were measured.

\section{Determination of blood glucose concentration}

Blood glucose concentration was determined in blood by Accuchek Performa ${ }^{\text {mit }}$ glucose strips in Accu-chek Performa ${ }^{\text {mim }}$ Test Meter (Roche, USA). The glucose levels were expressed as $\mathrm{mg} / \mathrm{dl}$.

\section{Statistical analysis}

Statistical differences between the treatments and the controls were tested by one-way analysis of variance (ANOVA) followed by the StudentNewman-Keuls test using the "OriginPro"statistic computer program. A difference in the mean values of $\mathrm{p}<0.05$ or less was considered to be statistically significant. Values of in vitro studies are expressed as mean \pm SD. Values of in vivo studies are presented as mean \pm SEM.

\section{RESULTS}

\section{Designing monograph for Rosmarinus officinalis (Linn.)}

\section{Macroscopic examination}

It is a branched, bushy perennial sub-shrub attaining a height of about 1 $\mathrm{m}$. The leaves are opposite, old branches are brown and flowers are pale blue or light lilac (Figure 1 A, B). The leaves are sessile, tough, and linear to linear-lanceolate, $1 \mathrm{~cm}$ to $4 \mathrm{~cm}$ long and $2 \mathrm{~mm}$ to $4 \mathrm{~mm}$ wide, with recurved edges. The upper surface is dark green, glabrous and grainy, the lower surface is greyish-green and densely tomentose with a prominent midrib (Figure $1 \mathrm{~B}, \mathrm{C}$ ).

\section{Microscocopic examination}

Microscopic examination of powdered Rosemary leaves revealed the following diagnostic key elements (Figure 2). (1) Fragments of the lower epidermis showing sinuous walled cells and frequently occurring diacytic stomata. (2) conical shaped covering trichomes. (3) The typical glandular trichome of the labiate- type having a short unicellular stalk and a head composed of 8 cells sharing a common cuticle. (4) Abundant covering trichomes of the branched type interspersed forming a crowded felted masse. These covering trichomes are multicellular, thin walled, uniseriate, and much branched. (5) Fragments of the leaf upper epidermis showing cells with polygonal to irregular with slightly thickened walls and occasional pits.

\section{Assay of Rosemary leaves for the essential oil content}

The oil yield for R.officinalis (Linn.) collected at different months are represented in Table 1 . should be $1.2 \%$ at minimum according to the $\mathrm{BP}$ 2013. Therefore, R-MR, R-JN and R-SP showed the closest average yields to the limit specified (Table 1). However, the yields of REO obtained in the current study $(0.83 \pm 0.15$ to $1.79 \pm 0.44 \%)$ were higher than REO yields reported in literature. It was previously reported that the yield of REO ranged from 0.37 to $1.5 \%{ }^{29,30}$

\section{Spectrophotometric assay of Rosemary leaves for the total} hydroxycinnamic acid derivatives expressed as Rosmarinic acid

Results for the assay of Rosemary leaves for total hydroxycinnamic acid derivatives expressed as rosmarinic acid values are demonstrated in (Table 2). The values ranged from (1.25 g\%) for (R-JN) to (1.9g \%) for (R-MR).

Inspection of samples of Rosemary leaves for foreign matter content

Foreign matter content in Rosemary samples ranged from (1.9 g\%) for (R-AP) to (3.4 g\%) for (R-SP) as shown in (Table 3).
Table 1: Yield of REO obtained by hydro-distillation from Rosemary samples

\begin{tabular}{cccccc}
\hline SAMPLE & R-AG & R-MR & R-AP & R-JN & R-SP \\
\hline \multirow{2}{*}{ Yield $^{*}(\mathrm{v} / \mathrm{w} \%)$} & $0.83 \pm$ & $1.16 \pm$ & $0.83 \pm$ & $1.11 \pm$ & $1.79 \pm$ \\
& 0.15 & 0.05 & 0.25 & 0.10 & 0.44 \\
\hline
\end{tabular}

${ }^{\star}$ Yield expressed as $\mathrm{ml}$ per $100 \mathrm{~g}$ of fresh plant material. Values expressed as mean \pm SD $(n=3)$

\section{Table 2: Total hydroxycinnamic acid derivatives in Rose- mary samples}

\begin{tabular}{cccccc}
\hline SAMPLE & R-AG & R-MR & R-AP & R-JN & R-SP \\
\hline Rosmarinic acid $(\mathrm{g} \%)^{*}$ & 1.3 & 1.9 & 2.2 & 1.25 & 1.22 \\
\hline
\end{tabular}

* Total hydroxycinnamic acid derivatives expressed as Rosmarinic acid g\% ( $\mathrm{g}$ in $100 \mathrm{~g}$ of dry Rosemary leaves)

Table 3: Foreign matter content in Rosemary samples

\begin{tabular}{cccccc}
\hline SAMPLE & R-AG & R-MR & R-AP & R-JN & R-SP \\
\hline Foreign matter (g\%)* & 2.3 & 3.1 & 1.9 & 2.5 & 3.4 \\
\hline
\end{tabular} $\begin{aligned} & \text { * Foreign matter of foreign organs and elements expressed as } \mathrm{g} \% \text { (g in 100g of } \\
& \text { fresh Rosemary leaves) }\end{aligned}$

Table 4: Moisture content in Rosemary samples

\begin{tabular}{cccccc}
\hline SAMPLE & R-AG & R-MR & R-AP & R-JN & R-SP \\
\hline Moisture $(\% \mathrm{v} / \mathrm{w})^{*}$ & 4.7 & 7.2 & 6.5 & 6.0 & 7.8 \\
\hline
\end{tabular}

${ }^{\star}$ Moisture content expressed as $\mathrm{ml} / 100 \mathrm{~g}$ of Rosemary leaves

\section{Moisture content in samples of Rosemary leaves}

Water content in Rosemary samples are listed in (Table 4). The values ranged from $4.7 \%$ for R-AG to $7.8 \%$ for R-SP.

Chromatographic analysis of the essential oil obtained from Rosemary leaves

\section{Thin layer chromatography of REO}

Thin layer chromatography of REO from all the five samples (R-AG, $\mathrm{R}-\mathrm{MR}, \mathrm{R}-\mathrm{AP}, \mathrm{R}-\mathrm{JN}$, and R-SP) showed violet-blue zones corresponding to Borneol, and intense blue zones corresponding to 1,8-Cineole. Low intensity bluish-grey zones corresponding to Bornyl acetate also appeared (Figure 3).

\section{Gas Chromatography-Mass Spectrometry of REO}

The GC-MS analysis of REO obtained from the five samples of Rosemary (R-AG, R-MR, R-AP, R-JN, and R-SP) are represented in Table 5. The oil is composed mainly of monoterpenes. Oxygenated compounds identified in REO obtained from Rosemary samples are represented in Table 6. Ketones represented the highest proportion of oxygenated compounds. Regarding the individual components of the EO, Camphor, 1,8-Cineole and $\alpha$-Pinene were the 3 most abundant compounds identified in the 5 samples (Figure 4). Chromatograms of REO from the five samples are shown in figures 20,21,22, 23, and 24.

Physiochemical properties of the essential oil obtained from Rosemary samples

The relative density of REO from the five studied samples were in the range of $(0.897-0.908)$. As for the refractive indices, they were in the range of $(1.464-1.471)$. The optical rotation values for REO were found to be in the range of $\left(+6 \cdot 17^{\circ}\right.$ to $\left.+7 \cdot 20^{\circ}\right)$. Chemical properties for EOs include the acid value. It was less than 1 for all the tested samples, (Table 7). 
Table 5: Identification and quantification of compounds detected in REO obtained from Rosemary samples

\begin{tabular}{|c|c|c|c|c|c|c|}
\hline \multirow{2}{*}{ R.T. } & \multirow{2}{*}{ Compound } & \multicolumn{5}{|c|}{$\%$ of total } \\
\hline & & R-AG & R-MR & R-AP & R-JN & R-SP \\
\hline 9.72 & $a$-Pinene ${ }^{b}$ & $11.56 \pm 0.19$ & $8.61 \pm 0.11$ & $4.18 \pm 0.08$ & $9.66 \pm 0.15$ & $10.27 \pm 0.43$ \\
\hline 10.71 & Camphene $^{\mathrm{b}}$ & $4.85 \pm 0.19$ & $7.78 \pm 0.11$ & $2.66 \pm 0.13$ & $4.98 \pm 0.19$ & $5.16 \pm 0.08$ \\
\hline 12.83 & $\beta$-Pinene ${ }^{b}$ & $1.92 \pm 0.00$ & $6.99 \pm 0.05$ & $3.43 \pm 0.07$ & $3.45 \pm 0.29$ & $1.88 \pm 0.08$ \\
\hline 14.37 & $\beta$-Myrcene ${ }^{b}$ & $3.24 \pm 0.21$ & $4.24 \pm 0.03$ & $1.13 \pm 0.30$ & $2.28 \pm 0.02$ & $2.51 \pm 0.23$ \\
\hline 15.11 & $a$-Phellandrene ${ }^{b}$ & $0.78 \pm 0.07$ & $0.71 \pm 0.01$ & $0.31 \pm 0.01$ & $1.06 \pm 0.07$ & $0.79 \pm 0.20$ \\
\hline 15.55 & 3 -Carene $(\delta \text {-3-Carene })^{b}$ & $0.31 \pm 0.04$ & $0.21 \pm 0.00$ & $1.10 \pm 0.02$ & - & - \\
\hline 16.12 & $\delta$-Teroinene $\mathrm{b}^{\mathrm{b}}$ & $0.52 \pm 0.04$ & $0.47 \pm 0.01$ & $0.47 \pm 0.05$ & $0.49 \pm 0.06$ & $0.42 \pm 0.09$ \\
\hline 16.77 & p-Cymene ${ }^{b}$ & $0.87 \pm 0.05$ & $\pm 0.61 \pm 0.02$ & $0.73 \pm 0.04$ & $0.16 \pm 0.05$ & $0.56 \pm 0.01$ \\
\hline 17.06 & Limonene $^{\text {a }}$ & $3.61 \pm 0.21$ & $4.34 \pm 0.04$ & $2.43 \pm 0.09$ & $4.11 \pm 0.29$ & $3.66 \pm 0.05$ \\
\hline 17.22 & 1,8-cineole (Eucalyptol) & $18.27 \pm 0.07$ & $11.17 \pm 0.17$ & $23.25 \pm 0.06$ & $13.26 \pm 0.08$ & $13.44 \pm 0.17$ \\
\hline 19.53 & $\alpha$-Terpinen ${ }^{b}$ & $0.84 \pm 0.07$ & $\begin{array}{c}0.9 \\
3 \pm 0.01\end{array}$ & $1.13 \pm 0.08$ & $0.98 \pm 0.01$ & $0.89 \pm 0.14$ \\
\hline 20.43 & $\gamma$-Terpinen ${ }^{b}$ & $0.13 \pm 0.00$ & $0.23 \pm 0.01$ & $0.00 \pm 0.00$ & $0.29 \pm 0.05$ & $0.08 \pm 0.01$ \\
\hline 22.85 & Ocimene $^{b}$ & $0.11 \pm 0.01$ & $0.17 \pm 0.01$ & $0.17 \pm 0.01$ & $0.14 \pm 0.06$ & $0.08 \pm 0.01$ \\
\hline 23.07 & 4-Carene ${ }^{b}$ & $2.33 \pm 0.14$ & $0.44 \pm 0.01$ & $1.31 \pm 0.05$ & $1.15 \pm 0.12$ & $0.49 \pm 0.08$ \\
\hline 24.54 & $\beta$-Phellandrene ${ }^{\mathrm{b}}$ & $0.05 \pm 0.00$ & $0.07 \pm 0.00$ & $0.08 \pm 0.01$ & $0.10 \pm 0.06$ & $0.05 \pm 0.01$ \\
\hline 24.64 & Chrysanthenone ${ }^{b}$ & $1.23 \pm 0.07$ & $0.70 \pm 0.01$ & $0.09 \pm 0.00$ & $0.42 \pm 0.04$ & $0.41 \pm 0.02$ \\
\hline 25.88 & Camphor $^{\mathrm{b}}$ & $25.35 \pm 0.03$ & $25.76 \pm 0.25$ & $16.78 \pm 0.03$ & $25.65 \pm 0.34$ & $31.31 \pm 0.20$ \\
\hline 26.26 & cis-Carveol $^{\mathrm{b}}$ & $0.47 \pm 0.08$ & $0.43 \pm 0.01$ & $0.26 \pm 0.05$ & $0.40 \pm 0.07$ & $0.50 \pm 0.09$ \\
\hline 27.23 & cis-Pinocamphone $^{\mathrm{b}}$ & $0.25 \pm 0.01$ & $0.03 \pm 0.04$ & $0.10 \pm 0.00$ & $0.03 \pm 0.00$ & $0.05 \pm 0.03$ \\
\hline 27.39 & $a$-Pinocarvone ${ }^{b}$ & $0.17 \pm 0.04$ & $0.16 \pm 0.00$ & $0.18 \pm 0.07$ & $0.13 \pm 0.03$ & $0.25 \pm 0.14$ \\
\hline 27.57 & Borneol $^{b}$ & $6.08 \pm 0.06$ & $5.54 \pm 0.03$ & $5.30 \pm 0.04$ & $2.24 \pm 0.16$ & $9.25 \pm 0.49$ \\
\hline 28.16 & trans-Pinocamphone ${ }^{\mathrm{b}}$ & $0.99 \pm 0.01$ & $0.60 \pm 0.01$ & $1.12 \pm 0.00$ & $0.43 \pm 0.02$ & $0.47 \pm 0.05$ \\
\hline 28.55 & 4-Terpineol ${ }^{\mathrm{b}}$ & $1.18 \pm 0.14$ & $0.96 \pm 0.02$ & $1.36 \pm 0.06$ & $1.00 \pm 0.00$ & $1.30 \pm 0.06$ \\
\hline 29.62 & $\alpha$-Terpineol ${ }^{b}$ & $1.90 \pm 0.08$ & $1.69 \pm 0.02$ & $4.43 \pm 0.02$ & $1.88 \pm 0.06$ & $2.81 \pm 0.06$ \\
\hline 30.05 & Myrtenol $^{\mathrm{b}}$ & $0.24 \pm 0.06$ & $0.15 \pm 0.00$ & $0.23 \pm 0.00$ & $0.17 \pm 0.00$ & $0.29 \pm 0.01$ \\
\hline 30.82 & Verbenone $^{\mathrm{b}}$ & $3.32 \pm 0.16$ & $0.94 \pm 0.05$ & $0.81 \pm 0.06$ & $2.01 \pm 0.01$ & $5.50 \pm 0.15$ \\
\hline 36.33 & Bornyl acetate ${ }^{b}$ & $2.70 \pm 0.08$ & $6.97 \pm 0.03$ & $10.51 \pm 0.08$ & $4.19 \pm 0.01$ & $2.92 \pm 0.24$ \\
\hline 44.71 & $\beta$-Caryophyllene ${ }^{b}$ & $1.10 \pm 0.02$ & $1.15 \pm 0.03$ & $3.78 \pm 0.08$ & $3.24 \pm 0.08$ & $0.61 \pm 0.21$ \\
\hline 46.82 & a-Caryophyllene & $0.71 \pm 0.00$ & $1.16 \pm 0.07$ & $0.89 \pm 0.12$ & $1.24 \pm 0.01$ & $0.18 \pm 0.07$ \\
\hline
\end{tabular}


Table 5: Con

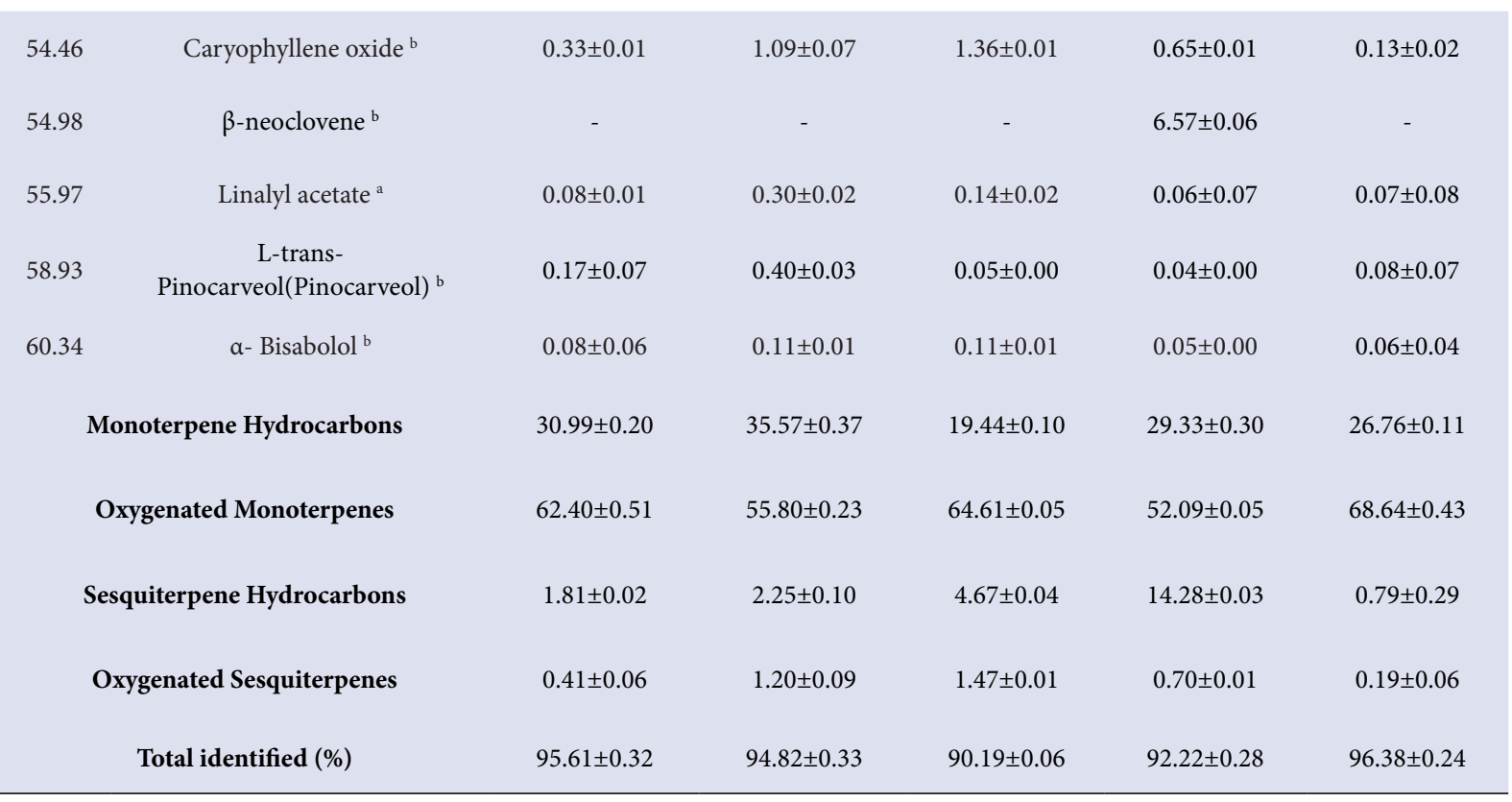

Compounds were identified by comparing their retention indices with those of standards ${ }^{a}$ or on the basis of their mass spectral fragmentation using those stored in the spectrometer database (MS library-NIST05)

R.T.: retention time in minutes; values are given as mean $\pm \mathrm{SD}(\mathrm{n}=3)$

Table 6: Oxygenated compounds identified in REO obtained from Rosemary samples

\begin{tabular}{cccccc}
\hline & R-AG & R-MR & R-AP & R-JN & R-SP \\
\hline Alcohols & $10.12 \pm 0.39$ & $9.28 \pm 0.14$ & $11.74 \pm 0.04$ & $5.78 \pm 0.15$ & $14.29 \pm 0.47$ \\
Ethers & $18.61 \pm 0.06$ & $12.25 \pm 0.1$ & $24.61 \pm 0.06$ & $13.91 \pm 0.07$ & $13.58 \pm 0.18$ \\
Ketones & $30.08 \pm 0.16$ & $27.49 \pm 0.14$ & $19.07 \pm 0.15$ & $29.33 \pm 0.35$ & $38.50 \pm 0.01$ \\
Esters & $2.96 \pm 0.08$ & $7.27 \pm 0.05$ & $10.65 \pm 0.06$ & $4.25 \pm 0.08$ & $2.99 \pm 0.16$ \\
Total & $62.81 \pm 0.69$ & $57.00 \pm 0.44$ & $66.08 \pm 0.32$ & $52.79 \pm 0.65$ & $68.83 \pm 0.85$ \\
\hline
\end{tabular}

Values are given as mean $\pm \mathrm{SD}(\mathrm{n}=3)$

\section{Designing monograph for Lavandula angustifolia (Linn.)}

\section{Macroscopic examination}

Branched aromatic shrub, 1-2 $\mathrm{m}$ high (Figure 5, A). The branches are grey brown to dark brown with long flowering and short leafy shoots $(\mathrm{A}, \mathrm{B})$. The flower has a short peduncle and consists of a bluish-grey tubular calyx 4-7 mm long with longitudinal ribs $(\mathrm{C})$, and a blue bilabial corolla, with the upper lip straight and bifid (2 large lobes) and the lower lip spreading and trilobite ( 3 smaller lobes) (C, D). The leaves have very short petiole and a linear-lanceolate blade $17 \mathrm{~mm}$ long and $2 \mathrm{~mm}$ wide (A).

\section{Microscopic examination}

Microscopic examination of powdered L. angustifolia (Linn.) (Lavender) flowers showed the following diagnostic key elements, parenchyma cells containing calcium oxalate crystals (1); fragments of the calyx epidermis with sinuous walled cells and containing prismatic crystals of calcium oxalate (2); the labiate type glandular trichome in surface view (3) and side view (4) which are characterized by the short unicellular stalks and the heads of 8 radiating cells; glandular trichomes with uniseriate multicellular stalks and unicellular heads $(5,6)$; covering trichomes bifurcating at one or more levels (7); spherical pollen grains having exines with 6 slit like germinal pores, also known as hexacolpate pollen grains (8) (Figure 6).

\section{Assay of Lavender flower for the essential oil content}

Assay of Lavender flowers for their yields of EO revealed that higher yield was obtained from L-JL (3.20 $\pm 0.59 \%)$. However, LEO yield was $(2.67 \pm 0.53 \%)$ for L-SP (Table 8$)$.

\section{Inspection of samples of Lavender flowers for foreign matter and} moisture content

Inspection for foreign matter in Lavender samples have shown that (L$\mathrm{SP}$ ) and (L-JL) contained $2.1 \mathrm{~g} \%$ and $1.4 \mathrm{~g} \%$ respectively (Table 9). As for the water content, (L-SP) and (L-JL) had (7.2\%) and (8.5\%) of moisture respectively (Table 10). 
Table 7: Physiochemical properties of REO from Rosemary samples

\begin{tabular}{cccccc}
\hline & R-AG & R-MR & R-AP & R-JN & R-SP \\
\hline $\begin{array}{c}\text { Relative } \\
\text { Density }\end{array}$ & 0.901 & 0.90 & 0.897 & 0.908 & 0.901 \\
$\begin{array}{c}\text { Refractive } \\
\text { Index }\end{array}$ & 1.469 & 1.465 & 1.465 & 1.464 & 1.468 \\
$\begin{array}{c}\text { Optical } \\
\text { Rotation }\end{array}$ & $+6.17^{\circ}$ & $+6.23^{\circ}$ & $+6.25^{\circ}$ & $+7.20^{\circ}$ & $+6.22^{\circ}$ \\
Acid Value & 0.39 & 0.44 & 0.44 & 0.33 & 0.50 \\
\hline
\end{tabular}

Table 8: Yield of LEO obtained by hydro-distillation from Lavender samples

\begin{tabular}{lll}
\hline SAMPLE & L-SP & L-JL \\
\hline Yield $(\%)^{*}$ & $2.67 \pm 0.53$ & $3.20 \pm 0.59$ \\
\hline
\end{tabular}

${ }^{*}$ Yield expressed as $\mathrm{ml}$ per $100 \mathrm{~g}$ weight of plant material. Values expressed as mean \pm SD $(n=3)$

Table 9: Foreign matter content in samples of Lavender flowers

\begin{tabular}{ccc}
\hline SAMPLE & L-SP & L-JL \\
\hline Foreign matter $(\mathrm{g} \%)^{*}$ & 2.1 & 1.4 \\
\hline
\end{tabular}

${ }^{*}$ Foreign matter of foreign organs and elements expressed as $\mathrm{g} \%$ ( $\mathrm{g}$ in 100g of Rosemary leaves)

\section{Table 10: Moisture content in samples of Lavender flow-} ers

\begin{tabular}{ccc}
\hline SAMPLE & L-SP & L-JL \\
\hline Moisture $(\% \mathrm{v} / \mathrm{w})^{*}$ & 7.2 & 8.5 \\
\hline
\end{tabular}

${ }^{*}$ Moisture content expressed as $\mathrm{ml} / 100 \mathrm{~g}$ of Lavender flowers

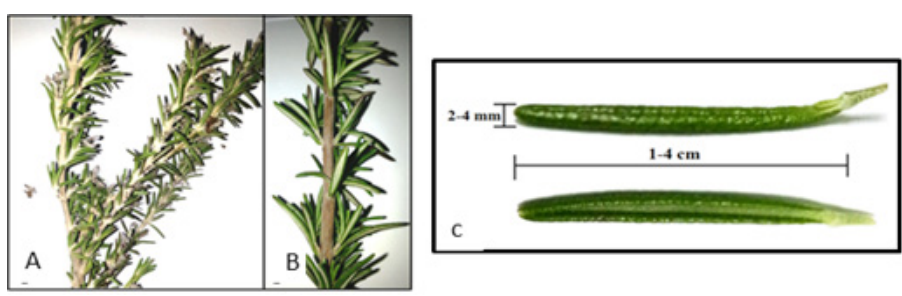

Figure 1: Macroscopic characteristics of Rosmarinus officinalis leaf.

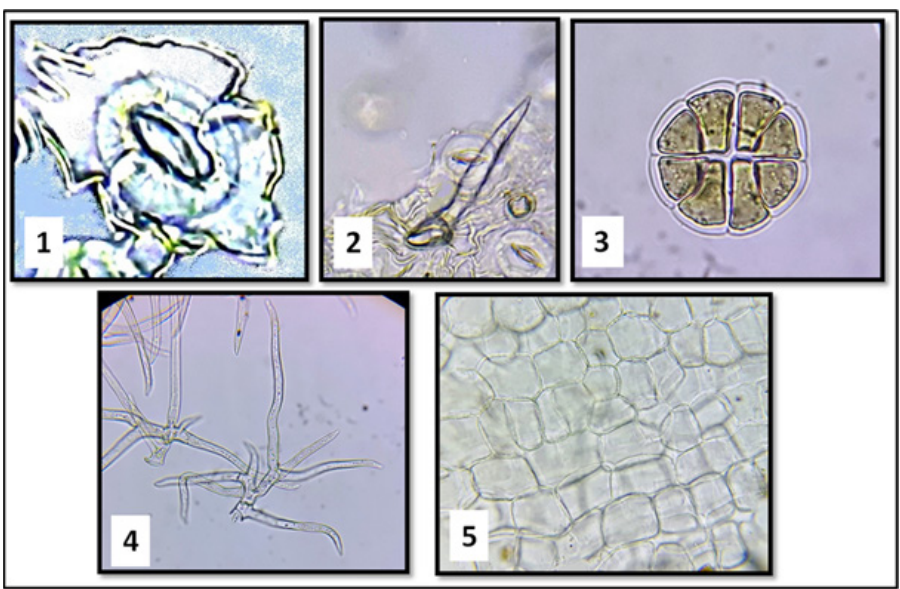

Figure 2: Illustration for microscopic examination of powdered Rosemary leaves. Lower epidermis with diacytic stomata (1); conical shaped covering trichomes (2); labiate type glandular trichome (3); branched covering trichomes (4); upper epidermis of the leaf (5).

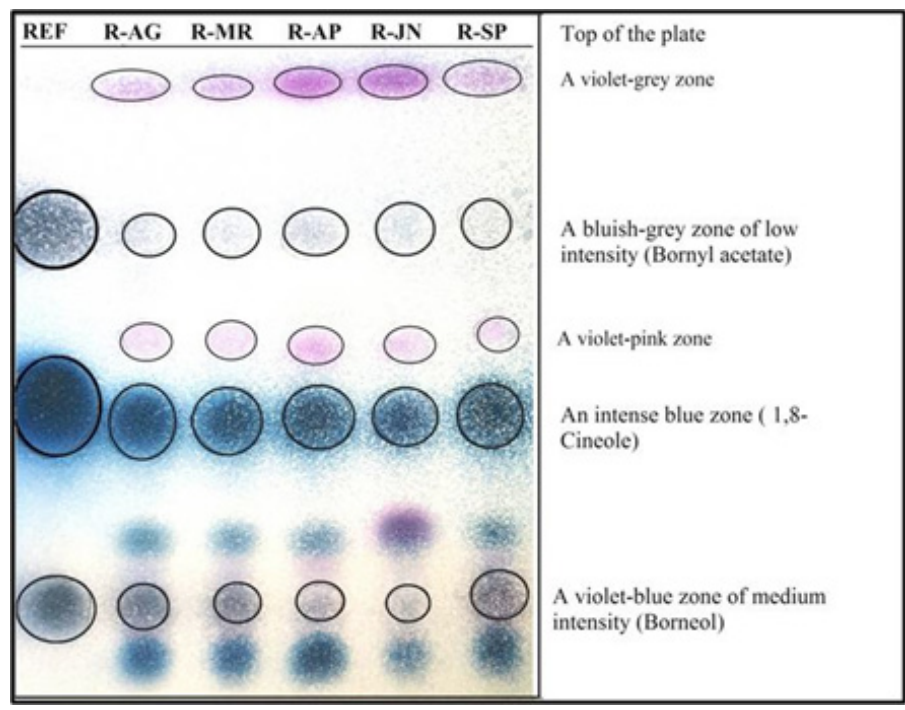

Figure 3: Thin layer chromatogram of REO obtained from the 5 Rosemary samples (R-AG, R-MR, R-AP, R-JN and R-SP); REF: reference solution containing standards: Borneol, 1,8-Cineole and Bornyl acetate; REO and standards dissolved in toluene; mobile phase: ethyl acetate, toluene (5:95 v/v); spraying reagent Vanillin/ $\mathrm{H} 2 \mathrm{SO} 4$, followed by heating for $10 \mathrm{~min}$ at $105^{\circ} \mathrm{C}$.
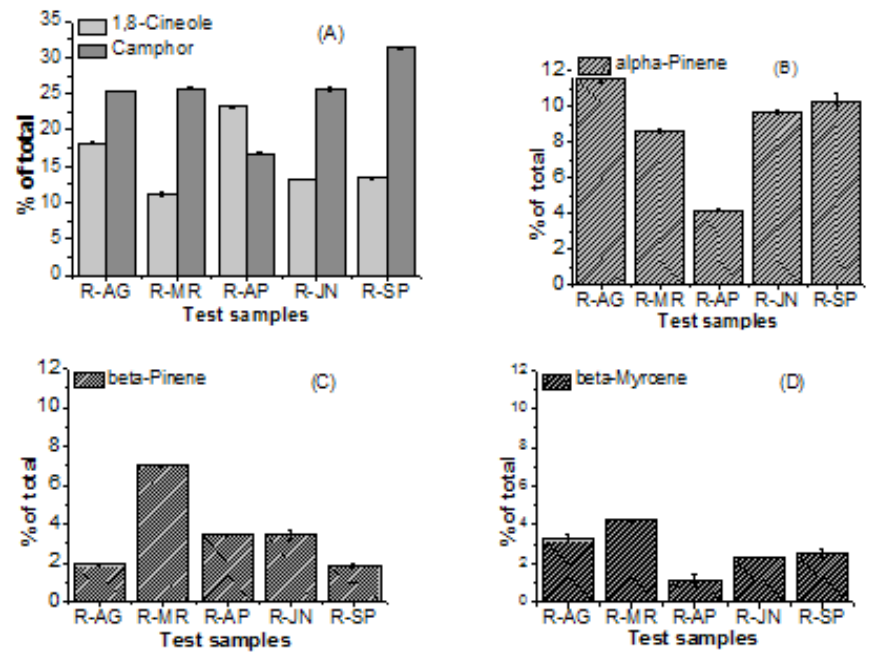

Figure 4: Comparison of 1,8-Cineole and Camphor contents (A), a-Pinene content (B), $\beta$-Pinene content (C), $\beta$-Myrcene content (D) in REO from different Rosemary samples. Values given as mean $\pm S D(n=3)$.

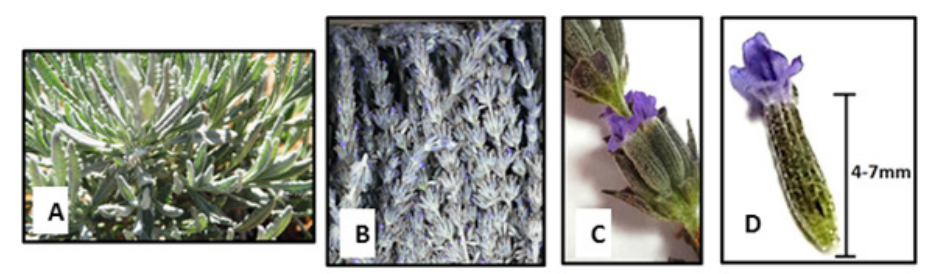

Figure 5: Macroscopic characteristics of the flower of Lavandula angustifolia. 


\section{Chromatographic analysis of the essential oil obtained} from Lavender flowers

Thin layer chromatography of LEO

Thin layer chromatography of LEO from both (L-SP) and (L-JL) showed violet zones corresponding to Linalool and 1,8-Cineole (Figure 7).

\section{Gas Chromatography-Mass Spectrometry of LEO}

The GC-MS analysis of the EO obtained from the two samples of Lavender revealed that the oil is composed mainly of monoterpenes. Sesquiterpenes represented only a small percentage relatively (Table 11). In both samples, oxygenated monoterpenes were present in greater amounts than monoterpene hydrocarbons (Table 11). Oxygenated compounds were mainly ethers, alcohols, and ketones. However, aldehydes and esters were present at trace amounts. Phenolics were absent (Table 12). The major components of LEO from both samples (L-SP and L-JL) were 1,8-Cineole, Limonene, $\beta$-Pinene, Terpinolene, Linalool, Camphor, $\alpha$-Pinene and Lavandulol (Table 11). Chromatograms of LEO from the two samples are shown in figures 25 and 26.

Physiochemical properties of the essential oil obtained from Lavander samples.

The values of relative density, refractive index, optical rotation and acid value for LEO from (L-SP) and (L-JL) are represented in Table 13.

\section{In vitro investigation of the antioxidant activity of Rosmarinus officinalis and Lavandula angustiflolia (Linn.) essential oils}

\section{DPPH free radical scavenging activity of REO obtained from Rosemary samples}

Assay of the DPPH free radical scavenging activity of REO from (R-AG, R-MR, R-AP, R-JN and R-SP) was carried out in a concentration-dependent manner (Figure 8). The antioxidant activity for REO was directly compared with the antioxidant activity of ascorbic acid $0.2 \mathrm{mg} / \mathrm{ml}$ (AA) as a positive control and with the vehicle, methanol, as a control. REO from (R-AG, R-MR, R-AP, R-JN and R-SP) showed significant DPPH free radical scavenging activity $(\mathrm{p}<0.5)$ in comparison to the control. Therefore, antioxidant potential of REO from all studied samples was confirmed. Moreover, the antioxidant activity of REO from all studied samples was both concentration and time dependent (Figure 9). At 60 minutes, the DPPH radical scavenging activity of REO from all test samples was higher. The maximum antioxidant activities, occurring at 60 minutes, for the 6 concentrations of each sample (Figure 9), were variable between the 5 samples. For all concentrations $(2.5,5,10,15,20$ and $25 \mu \mathrm{l} / \mathrm{ml}$ ), (R-AG) exhibited a DPPH free radical scavenging activity of (9.3 $\pm 0.56 \%),(20.25 \pm 0.70 \%),(20.11 \pm 0.70 \%),(83.72 \pm 0.14 \%),(86.35$ $\pm 0.56 \%)$, and $(93.3 \pm 0.7 \%)$, respectively. (R-MR) exhibited a DPPH free radical scavenging activity of (28.26 $\pm 0.70 \%),(39.88 \pm 0.21 \%),(59.47 \pm$ $0.17 \%),(60.25 \pm 0.28 \%),(91.26 \pm 0.70 \%)$, and $(91.31 \pm 0.42 \%)$. (R-AP) exhibited a DPPH free radical scavenging activity of $(46.57 \pm 0.70 \%)$, (78.80 $\pm 0.14 \%),(84.93 \pm 0.49 \%),(86.36 \pm 0.70 \%),(88.69 \pm 0.21 \%)$, and $(89.61 \pm 0.14 \%)$. (R-JN) exhibited a DPPH free radical scavenging activity of $(21.25 \pm 0.70 \%),(31.56 \pm 0.28 \%),(30.62 \pm 0.70 \%),(53.50 \pm 0.28 \%)$, $(57.49 \pm 0.70 \%)$, and $(59.81 \pm 0.70 \%)$. (R-SP) exhibited a DPPH free radical scavenging activity of $(42.40 \pm 0.21 \%),(53.56 \pm 0.21 \%),(76.48$ $\pm 0.70 \%),(84.57 \pm 0.14 \%),(87.49 \pm 0.70 \%)$, and $(94.61 \pm 0.70 \%) . \mathrm{IC}_{50}$ values for REO from the 5 samples presented in (Table 14), revealed that REO from (R-AP) had the highest antioxidant activity $\left(\mathrm{IC}_{50}=9.65\right.$ $\pm 1.03 \mu \mathrm{l})$, followed by REO from (R-MR) $\left(\mathrm{IC}_{50}=10.83 \pm 0.38 \mu \mathrm{l}\right)$, REO from (R-SP) $\left(\mathrm{IC}_{50}=11.32 \pm 0.5 \mu \mathrm{l}\right), \mathrm{REO}$ from $(\mathrm{R}-\mathrm{AG})\left(\mathrm{IC}_{50}=13.39 \pm 0.34\right.$ $\mu \mathrm{l})$ and REO from $(\mathrm{R}-\mathrm{JN})\left(\mathrm{IC}_{50}=17.1 \pm 0.29 \mu \mathrm{l}\right)$. Therefore, REO from
Table 11: Identification and quantification of compounds detected in LEO obtained from L.angustifolia samples

\begin{tabular}{|c|c|c|c|}
\hline \multirow{2}{*}{ R.T. } & \multirow{2}{*}{ Compound } & \multicolumn{2}{|c|}{$\%$ of total } \\
\hline & & L-SP & L-JL \\
\hline 4.75 & $a_{\text {-Pinene }}{ }^{b}$ & $1.86 \pm 0.07$ & $1.63 \pm 0.33$ \\
\hline 5.18 & Camphene $^{\mathrm{b}}$ & $0.29 \pm 0.23$ & $0.11 \pm 0.07$ \\
\hline 5.95 & $\beta$-Phellandrene ${ }^{b}$ & $1.28 \pm 0.02$ & $1.03 \pm 0.08$ \\
\hline 6.06 & $\beta$-Pinene ${ }^{b}$ & $4.65 \pm 0.48$ & $3.83 \pm 0.24$ \\
\hline 8.32 & Limonene $^{\text {a }}$ & $9.11 \pm 0.33$ & $8.58 \pm 0.06$ \\
\hline 9.02 & 1,8-Cineole ${ }^{a}$ & $64.99 \pm 0.92$ & $71.08 \pm 0.86$ \\
\hline 10.07 & $\gamma$-Terpinene ${ }^{b}$ & $0.46 \pm 0.27$ & $0.23 \pm 0.08$ \\
\hline 14.11 & Linalool a $^{a}$ & $3.49 \pm 0.04$ & $3.14 \pm 0.39$ \\
\hline 16.45 & Cis- $\alpha$-Farnesene ${ }^{b}$ & $0.05 \pm 0.07$ & $0.03 \pm 0.05$ \\
\hline 18.38 & Camphor ${ }^{\mathrm{b}}$ & $1.83 \pm 0.04$ & $1.61 \pm 0.40$ \\
\hline 20.21 & Borneol $^{b}$ & $0.69 \pm 0.12$ & $0.49 \pm 0.02$ \\
\hline 20.59 & Lavandulol $^{\mathrm{b}}$ & $1.36 \pm 0.09$ & $1.16 \pm 0.14$ \\
\hline 21.33 & m-Xylene ${ }^{b}$ & $0.60 \pm 0.09$ & $0.58 \pm 0.01$ \\
\hline 22.74 & Terpinolene $^{b}$ & $2.95 \pm 0.14$ & $3.09 \pm 0.60$ \\
\hline 23.26 & Myrtenol b & $0.19 \pm 0.01$ & $0.04 \pm 0.06$ \\
\hline 26.55 & Cuminaldehyde ${ }^{b}$ & $0.11 \pm 0.00$ & $0.03 \pm 0.04$ \\
\hline 28.63 & Linalyl acetate a & $0.06 \pm 0.04$ & $0.01 \pm 0.02$ \\
\hline 38.92 & Caryophyllene oxide b & $0.15 \pm 0.05$ & $0.04 \pm 0.05$ \\
\hline 42.08 & $\beta$-Myrcene ${ }^{b}$ & $0.06 \pm 0.00$ & $0.006 \pm 0.01$ \\
\hline 45.15 & Allo-Ocimene ${ }^{b}$ & $0.39 \pm 0.37$ & $0.15 \pm 0.00$ \\
\hline \multicolumn{2}{|c|}{ Monoterpene Hydrocarbons } & $21.05 \pm 1.09$ & $18.56 \pm 0.27$ \\
\hline \multicolumn{2}{|c|}{ Oxygenated Monoterpenes } & $72.72 \pm 1.30$ & $77.56 \pm 0.09$ \\
\hline \multicolumn{2}{|c|}{ Sesquiterpene Hydrocarbons } & $0.05 \pm 0.07$ & $0.03 \pm 0.05$ \\
\hline \multicolumn{2}{|c|}{ Oxygenated Sesquiterpenes } & $0.15 \pm 0.05$ & $0.04 \pm 0.05$ \\
\hline \multicolumn{2}{|l|}{ Others } & $0.60 \pm 0.09$ & $0.58 \pm 0.01$ \\
\hline \multicolumn{2}{|c|}{ Total Identified (\%) } & $94.57 \pm 2.16$ & $96.77 \pm 0.12$ \\
\hline
\end{tabular}

Compounds were identified by comparing their retention indices with those of standards $\mathrm{s}^{\mathrm{a}}$ or on the basis of their mass spectral fragmentation using those stored in the spectrometer database (MS library-NIST05)

R.T.: retention time in minutes; values are given as mean $\pm \mathrm{SD}(\mathrm{n}=3)$.

Table 12: Oxygenated compounds identified in LEO obtained from Lavender samples

\begin{tabular}{ccc}
\hline & \multicolumn{2}{c}{$\%$ of total } \\
\cline { 2 - 3 } Oxygenated compound class & L-SP & L-JL \\
\hline Alcohols & $5.73 \pm 0.50$ & $4.83 \pm 0.17$ \\
Ethers & $65.14 \pm 0.87$ & $71.12 \pm 0.81$ \\
Aldehydes & $0.11 \pm 0.00$ & $0.03 \pm 0.04$ \\
Ketones & $1.81 \pm 0.04$ & $1.61 \pm 0.40$ \\
Esters & $0.06 \pm 0.04$ & $0.01 \pm 0.02$ \\
Total & $72.85 \pm 1.38$ & $77.6 \pm 0.36$
\end{tabular}

Values given as mean $\pm \mathrm{SD}(\mathrm{n}=3)$ 
different samples collected at different seasons showed varying capacity in scavenging DPPH radical.

\section{$D P P H$ free radical scavenging activity of LEO from Lavender samples}

Assay of the DPPH free radical scavenging activity of LEO from the two samples was carried out in a concentration-dependent manner (Figure 10). The antioxidant activity for LEO was directly compared with the antioxidant activity of ascorbic acid $0.2 \mathrm{mg} / \mathrm{ml}$ (AA) as a positive control and with the vehicle, methanol, as a control. REO from (R-AG, R-MR, R-AP, R-JN and R-SP) showed significant DPPH free radical scavenging activity $(\mathrm{p}<0.5)$ in comparison to the control. Therefore, antioxidant potential of LEO from the studied samples was confirmed. The antioxidant activity of LEO was both concentration and time dependent (Figure 11). At 60 minutes, the DPPH radical scavenging activity was higher. The maximum antioxidant activities, occurring at 60 minutes, for the 6 concentrations of each sample (Figure 11), were variable for the 2 samples. In the current study, LEO from (L-SP) showed superior antioxidant activity over LEO from (L-JL) in the DPPH assay (Table 15).

\section{In vivo investigation of the antidiabetic effect of Rosmarinus officinalis (Linn.) essential oil}

In this study, various doses of the REO, obtained from (R-AP), were studied for their acute effects in alloxan-diabetic animals. REO at all doses $(80,100$ and $110 \mathrm{mg} / \mathrm{kg})$ showed a significant effect, with blood glucose levels dropped to $35.0,46.2$ and $47.5 \%$, respectively from that of control after $6 \mathrm{~h}$ (Table 16). In order to determine the subacute effects, three doses of REO were administered throughout 8 days consecutively. The blood glucose level of each animal was monitored on 1st, 3rd, 5th and 8th days after the administration of the test samples. In alloxan-induced diabetic mice, REO at all doses $(80,100$ and $110 \mathrm{mg} / \mathrm{kg})$ showed a significant effect, with blood glucose levels dropping to 36.7, 42.7 and 58.4 $\%$, respectively from that of diabetic control on the 8th day (Table 17).

\section{DISCUSSION}

Designing monographs for aromatic plants such as R. officinalis (Linn.), requires tests conducted both on the plant material and on the EO it produces. Macroscopic examination of the plant material represents the first step in its identification. The morphological features for Rosemary leaves from the current study (Figure 1) are identical to those described in the BP 2013..$^{23}$ Further investigation about the identity of the plant material requires looking for the diagnostic key elements under the microscope. Microscopic examination of powdered Rosemary leaves (Figure 2) revealed that the diagnostic key elements are similar to those reported in the BP $2013^{23}$ and in the textbook Jackson's Atlas of microscopy of medicinal plants. ${ }^{31}$

The oil yield for R. officinalis (Linn.) should be $1.2 \%$ at minimum according to the BP 2013. Therefore, R-MR, R-JN and R-SP showed the closest average yields to the limit specified (Table 1 ). However, the yields of REO obtained in the current study $(0.83 \pm 0.15$ to $1.79 \pm 0.44 \%)$ were higher than REO yields reported in literature. It was previously reported that the yield of REO ranged from 0.37 to $1.5 \% .^{29,30}$

Rosmarinic acid, a phenolic acid isolated from species of family Lamiaceae, has been identified as an active component of therapeutic values. It is an ester of caffeic acid (hydroxycinnamic acid).$^{32}$ Rosemary's reported pharmacological actions have been linked to its major chemical constituents including rosmarinic acid. ${ }^{33}$ In rosemary leaf, total hydroxycinnamic acid derivatives must not be less than ( $3 \mathrm{~g} \%$ ) expressed as rosmarinic acid. ${ }^{23}$ In the current study, results for the assay of Rosemary leaves for total hydroxycinnamic acid derivatives expressed as rosmarinic acid values are demonstrated in (Table 2). The values ranged from $(1.25 \mathrm{~g} \%)$ for (R-JN) to $(1.9 \mathrm{~g} \%)$ for (R-MR). Therefore, values were lower than
Table 13: Physiochemical properties of LEO obtained from Lavender samples

\begin{tabular}{ccc}
\hline & L-SP & L-JL \\
\hline Relative Density & 0.892 & 0.889 \\
Refractive Index & 1.459 & 1.464 \\
Optical Rotation & $-6.48^{\circ}$ & $-6.58^{\circ}$ \\
Acid Value & 0.62 & 0.63 \\
\hline
\end{tabular}

Table 14: DPPH free radical scavenging activity expressed as $I_{50}$ of REO from Rosemary samples

\begin{tabular}{cccccc}
\hline SAMPLE & R-AG & R-MR & R-AP & R-JN & R-SP \\
\hline $\mathrm{IC}_{50}(\mu \mathrm{l} /$ & $13.39 \pm$ & $10.83 \pm$ & $9.65 \pm$ & $17.1 \pm$ & $11.32 \pm 0.51$ \\
$\mathrm{ml})$ & 0.34 & 0.38 & 1.03 & 0.29 & \\
\hline
\end{tabular}

$\mathrm{IC}_{50}$ expressed as $\mu \mathrm{l}$ of REO per $\mathrm{ml}$ of vehicle

Table 15: DPPH free radical scavenging activity expressed as $I_{50}$ of LEO from Lavender samples

\begin{tabular}{ccc}
\hline SAMPLE & L-SP & L-JL \\
\hline $\mathrm{IC}_{50}(\mu \mathrm{L} / \mathrm{ml})$ & $17.43 \pm 0.24$ & $19.48 \pm 0.26$ \\
\hline
\end{tabular}

$\mathrm{IC}_{50}$ expressed as $\mu \mathrm{l}$ of LEO per $\mathrm{ml}$ of vehicle

Table 16: Acute effect of (REO) on blood glucose level in alloxaninduced diabetic mice

\begin{tabular}{cccccc}
\hline & \multirow{2}{*}{$\begin{array}{c}\text { Dose } \\
(\mathrm{mg} / \mathrm{kg}) \\
\end{array}$} & \multicolumn{5}{c}{ Mean blood glucose concentration \pm SEM $(\mathrm{mg} /$} \\
$\mathrm{dl})$
\end{tabular}

SEM mean standard error

${ }^{\star} \mathrm{p}<0.05$ significant from the control animals

${ }^{* *} \mathrm{p}<0.01$ significant from the control animals

those specified by the BP 2013. However, values in this study are higher than other reported values of $(0.7 \mathrm{~g} \%) .{ }^{34}$ Such variations could be linked to climatic and ecological factors. The lower levels of these acids don't compromise the antioxidant potential. It was reported that Rosmarinic acid content of $1.16 \mathrm{~g} \%$ contributed to appreciable antioxidant activity of the Rosemary extract in the DPPH assay. ${ }^{35}$

Herbal drugs should be free from insects, moulds, and other animal contamination. Foreign matter is material consisting of foreign organs or foreign elements such as matter not coming from the source plant. ${ }^{23}$ Inspection of foreign matter in Rosemary samples revealed that these samples contained less than ( $5 \mathrm{~g} \%$ ) of stems and others which is the limit 


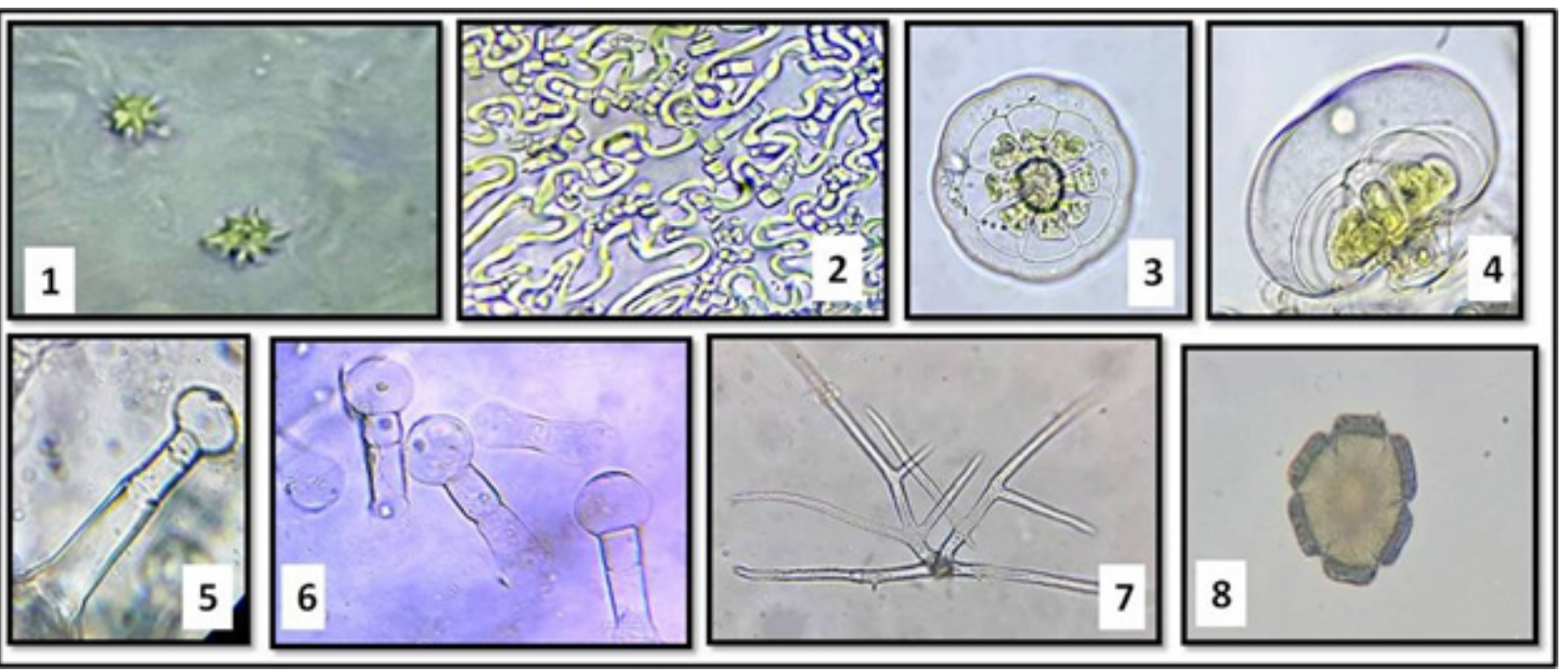

Figure 6: Illustration for microscopic examination of powdered Lavender flowers. Clusters of calcium oxalate(1); sinuous walled calyx epidermal cells containing prismatic crystals of calcium oxalate (2); labiate type glandular trichome in surface view(3) and side view (4); glandular trichomes (5,6); bifurcating covering trichomes(7); hexacolpate pollen grains (8).

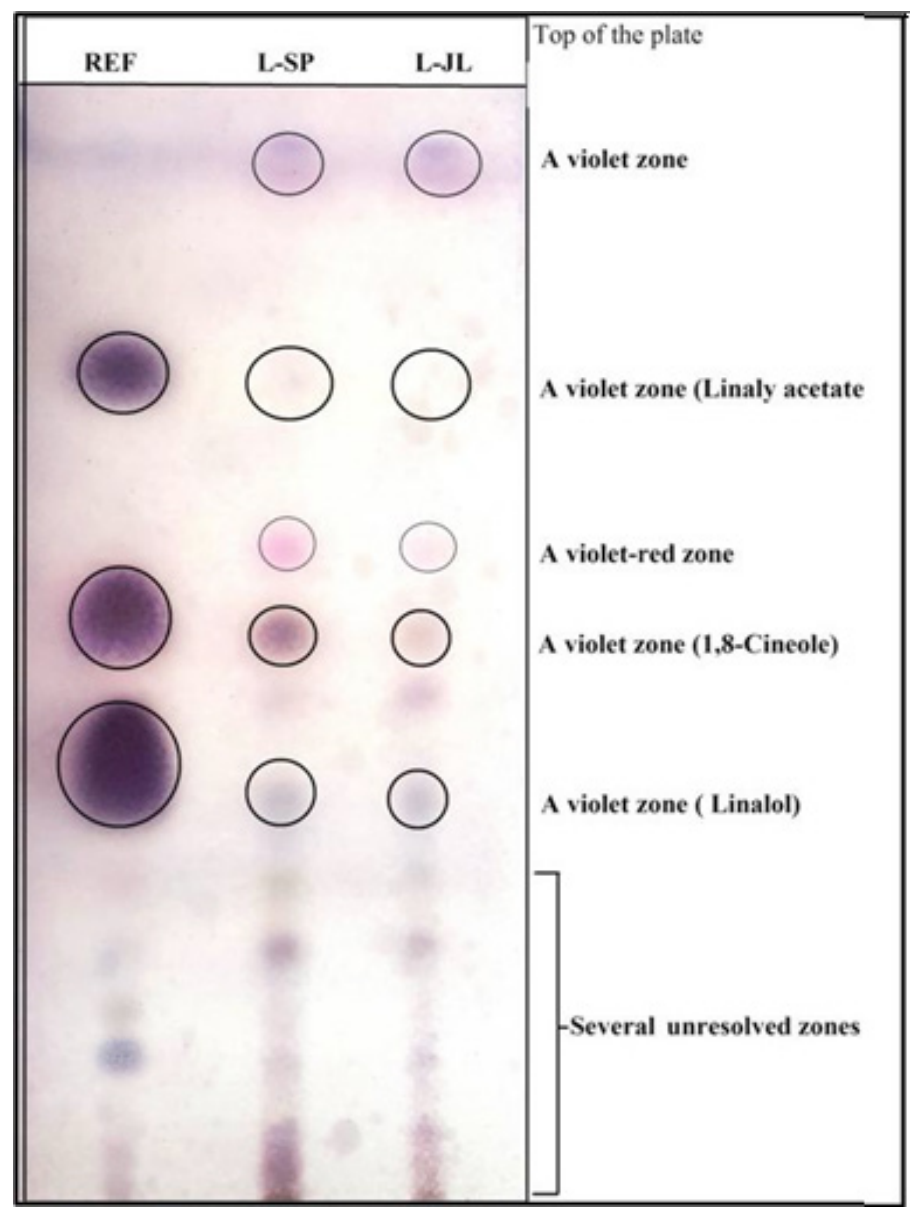

Figure 7: Thin layer chromatogram of LEO from the 2 Lavender samples (L-SP and L-JL); REF: Reference solution containing the standards: Linalol, 1,8-Cineole and Linalyl acetate); LEO and standards dissolved in toluene; mobile phase: ethyl acetate, toluene $(5: 95 \mathrm{v} / \mathrm{v})$; spraying reagent: Anisaldehyde/ $/ \mathrm{H} 2 \mathrm{SO} 4$ followed by heating for $10 \mathrm{~min}$ at $105^{\circ} \mathrm{C}$.
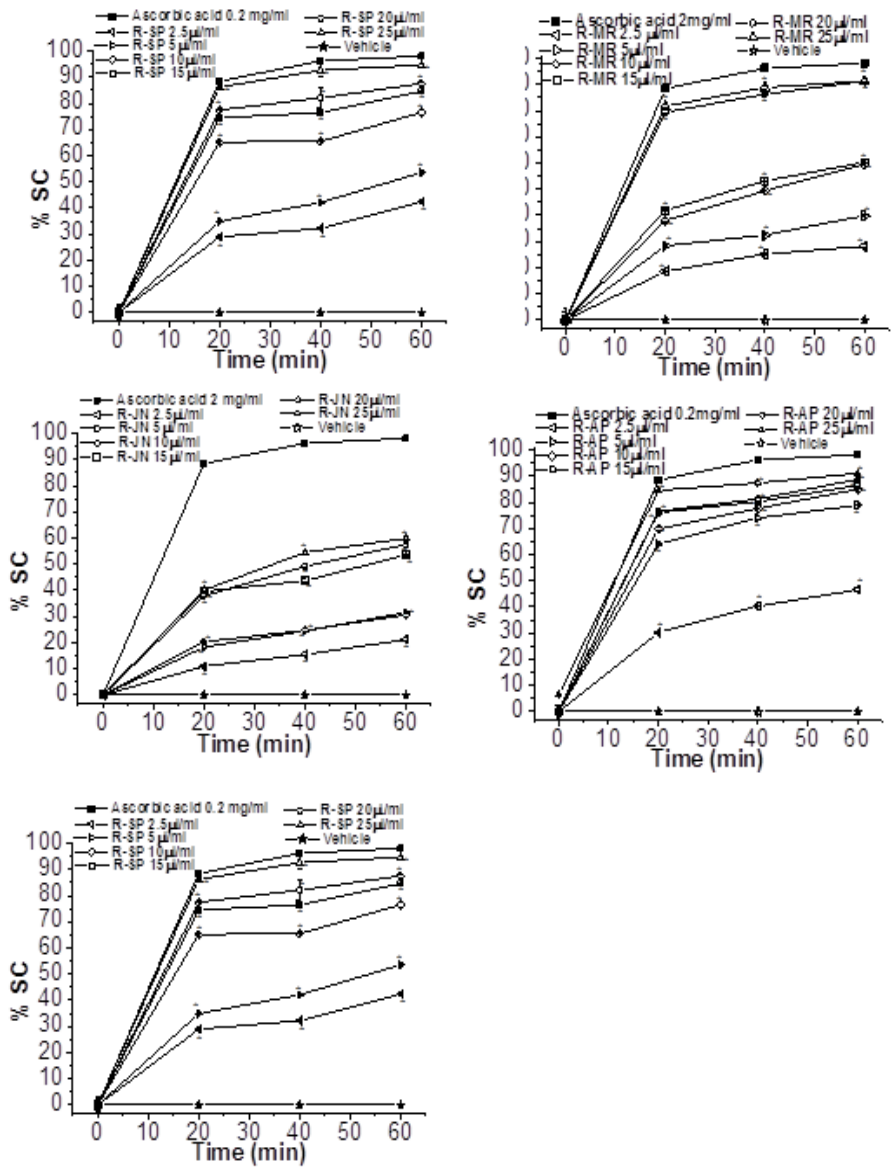

Figure 8: DPPH free radical scavenging activity of different concentrations of methanolic solutions of REO from Rosemary-August (R-AG), RosemaryMarch (R-MR), Rosemary-April (R-AP), Rosemary-June (R-JN), RosemarySeptember (R-SP). Ascorbic acid $0.2 \mathrm{mg} / \mathrm{ml}$ as a positive control; vehicle as a control; values are given as mean $\pm S D\left(n=3 /\right.$ group); ${ }^{*} \mathrm{P}<0.05$, when compared to the control. 
Table 17: Subacute effect of (REO) on blood glucose level in alloxaninduced diabetic mice

\begin{tabular}{|c|c|c|c|c|c|}
\hline \multirow{2}{*}{\multicolumn{2}{|c|}{$\begin{array}{c}\text { Dose } \\
(\mathrm{mg} / \mathrm{kg}) \\
1^{\text {st }} \text { day }\end{array}$}} & \multicolumn{4}{|c|}{ Mean blood glucose concentration \pm SEM $(\mathrm{mg} / \mathrm{dl})$} \\
\hline & & $3^{\text {rd day }}$ & $5^{\text {th }}$ day & $8^{\text {th }}$ day & \\
\hline Control & - & $\begin{array}{c}104.40 \pm \\
1.90\end{array}$ & $\begin{array}{c}118.70 \pm \\
3.60\end{array}$ & $\begin{array}{c}120.63 \pm \\
4.10\end{array}$ & $116.36 \pm 3.70$ \\
\hline $\begin{array}{c}\text { Diabetic } \\
\text { control }\end{array}$ & - & $\begin{array}{c}210.27 \pm \\
6.60\end{array}$ & $\begin{array}{c}205.42 \pm \\
7.30\end{array}$ & $\begin{array}{c}212.41 \pm \\
8.50\end{array}$ & $211.32 \pm 8.10$ \\
\hline GB & 5 & $\begin{array}{c}185.20 \pm \\
3.70\end{array}$ & $\begin{array}{c}178.03 \pm \\
2.90\end{array}$ & $\begin{array}{l}160.04 \\
\pm 2.40\end{array}$ & $\begin{array}{c}170.87 \pm \\
3.10^{\star *}\end{array}$ \\
\hline REO & 80 & $\begin{array}{c}135.43 \pm \\
3.46\end{array}$ & $\begin{array}{c}130.71 \pm \\
4.24\end{array}$ & $\begin{array}{c}153.57 \pm \\
6.70\end{array}$ & $\begin{array}{c}133.71 \pm \\
4.87^{\star}\end{array}$ \\
\hline REO & 100 & $\begin{array}{c}129.14 \pm \\
3.00\end{array}$ & $\begin{array}{c}126.29 \pm \\
3.08\end{array}$ & $\begin{array}{c}127.86 \pm \\
5.52\end{array}$ & $\begin{array}{c}121.14 \pm \\
4.92^{*}\end{array}$ \\
\hline REO & 110 & $\begin{array}{c}161.14 \pm \\
5.51\end{array}$ & $\begin{array}{c}147.14 \pm \\
4.07\end{array}$ & $\begin{array}{c}148.29 \pm \\
3.32\end{array}$ & $88.00 \pm 3.46^{*}$ \\
\hline
\end{tabular}

SEM mean standard error

${ }^{*} \mathrm{p}<0.05$ significant from the control animals

${ }^{* *} \mathrm{p}<0.01$ significant from the control animals

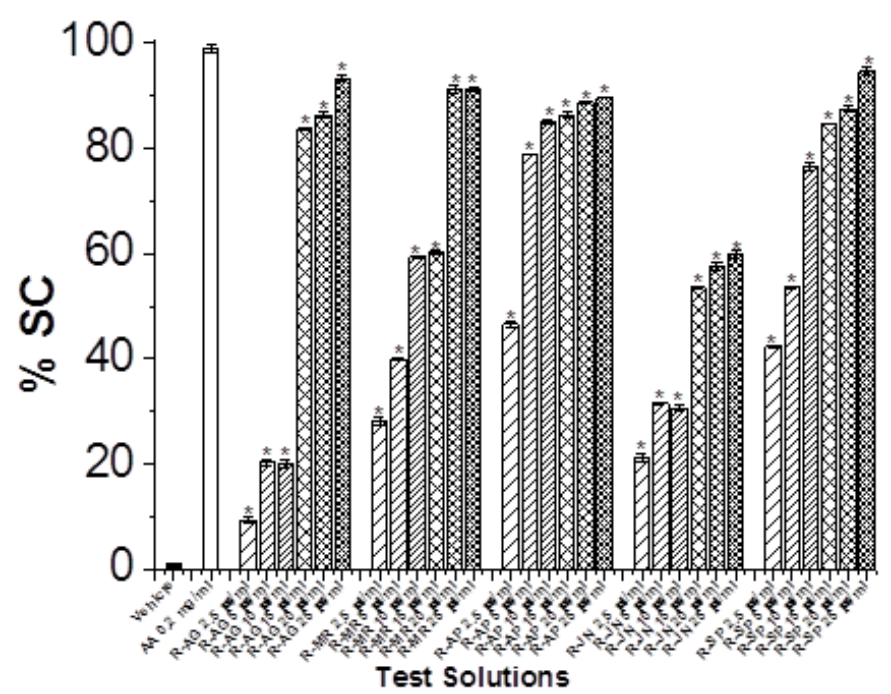

Figure 9: DPPH Free radical scavenging activity (\%) of REO from the 5 samples (R-AG, R-MR, R-AP, R-JN and R-SP). Ascorbic acid $0.2 \mathrm{mg} / \mathrm{ml}(\mathrm{AA})$ as a positive control; vehicle as a control; values are given as mean $\pm S D(n=3 /$ group); ${ }^{*} \mathrm{P}<0.05$, when compared to the control.

specified for Rosemary leaves by the BP 2013. The values ranged from (1.9 $\mathrm{g} \%$ ) for (R-AP) to (3.4 g\%) for (R-SP) as shown in (Table 3).

The values of water content in Rosemary samples, listed in Table 4., ranged from $4.7 \%$ for R-AG to $7.8 \%$ for R-SP. All values were within limits (< 10\%) specified by BP 2013.

Thin layer chromatography of REO from all the five samples (R-AG, R-MR, R-AP, R-JN, and R-SP) showed zones corresponding to Borneol, 1,8-Cineole and Bornyl acetate (Figure 3). These results were similar to the results described on the BP 2013 in which REO is described to consist of Borneol, 1,8-Cineole and Bornyl acetate as three of its major components. ${ }^{23}$

The GC-MS analysis of REO obtained from the five samples of Rosemary (R-AG, R-MR, R-AP, R-JN, and R-SP) are represented in Tables 5 and
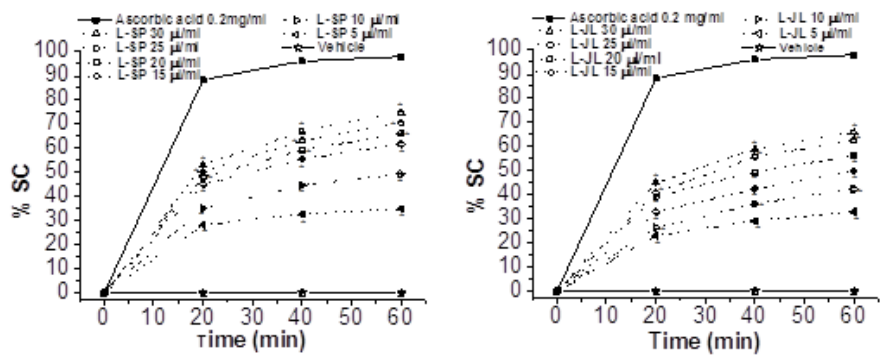

Figure 10: DPPH free radical scavenging activity of different concentrations of methanolic solutions of LEO from Lavender-September (L-SP) and Lavender-July (L-JL). Ascorbic acid $0.2 \mathrm{mg} / \mathrm{ml}$ as a positive control; vehicle as a control; values are given as mean $\pm S D$ ( $n=3$ /group); ${ }^{*} P<0.05$, when compared to the control.

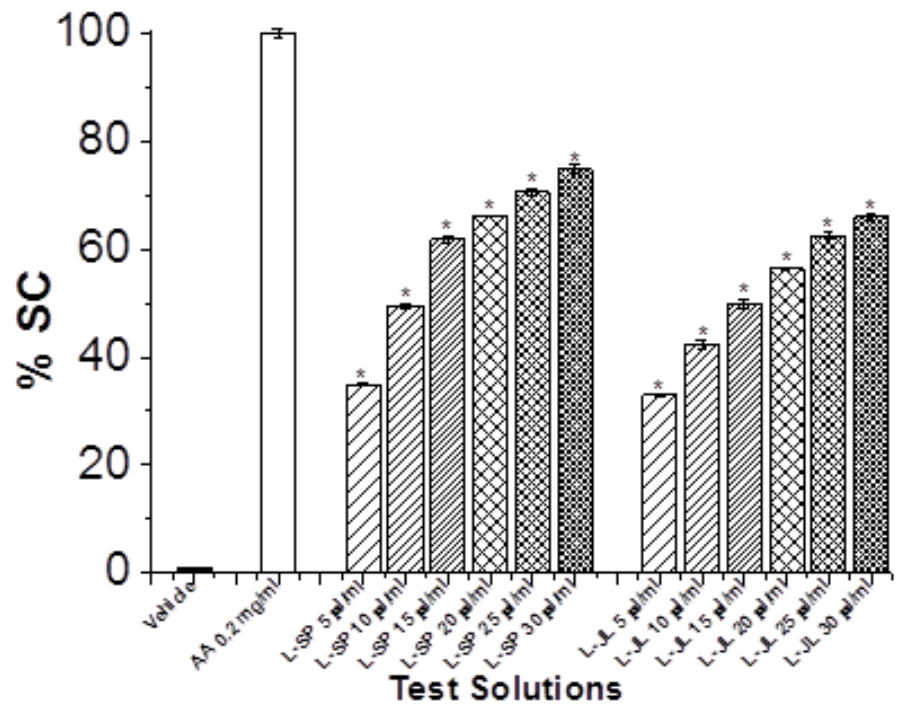

Figure 11: DPPH Free radical scavenging activity (\%) of LEO from the 2 samples (L-SP and R-JL). Ascorbic acid $0.2 \mathrm{mg} / \mathrm{ml}$ (AA) as a positive control; vehicle as a control; values are given as mean $\pm \mathrm{SD}$; ${ }^{\mathrm{P}}<0.05$, when compared to the control.

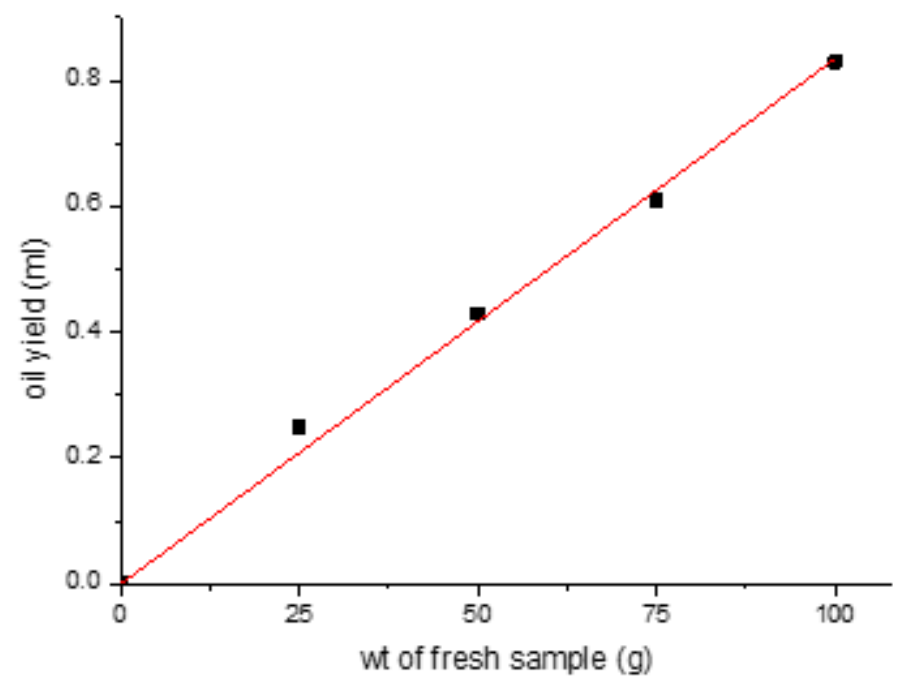

Figure 12: Calibration curve for essential oil yield of R-AG. 
Table 18: Comparison between monographs of the current study with those reported in BP2013

\begin{tabular}{|c|c|c|}
\hline Rosmarinus officinalis & BP 2013 & BAU botanical garden \\
\hline Morphological features & $\begin{array}{l}\text { The leaves are sessile, tough, and linear to linear-lanceolate, } 1 \mathrm{~cm} \text { to } \\
4 \mathrm{~cm} \text { long and } 2 \mathrm{~mm} \text { to } 4 \mathrm{~mm} \text { wide, with recurved edges. The upper } \\
\text { surface is dark green, glabrous and grainy, the lower surface is } \\
\text { greyish-green and densely tomentose with a prominent midrib. }\end{array}$ & As mentioned \\
\hline Microscopical characteristics & $\begin{array}{l}\text { Lower epidermis with diacytic stomata; conical shaped covering } \\
\text { trichomes; labiate type glandular trichome ; branched covering } \\
\text { trichomes; upper epidermis of the leaf }\end{array}$ & As mentioned \\
\hline $\begin{array}{l}\text { Total hydroxycinnamic derivatives, expressed as } \\
\text { rosmarinic acid }\end{array}$ & Minimum 3\% (anhydrous drug) & 1.22 to $1.9 \%$ \\
\hline Thin layer chromatography & 1,6-Cineole, Borneol, Bornyl acetate & Present \\
\hline Foreign matter & Maximum 5\% & 1.9 to $3.4 \%$ \\
\hline Moisture content & Maximum $100 \mathrm{~mL} / \mathrm{kg}$ & 4.7 to $7.8 \%$ \\
\hline Essential oil yield & Minimum $12 \mathrm{~mL} / \mathrm{kg}$ of essential oil (anhydrous drug) & 8.3 to $17.9 \mathrm{~mL} / \mathrm{kg}$ \\
\hline $\begin{array}{l}\text { Gas chromatography analysis of the essential } \\
\text { oil, }\end{array}$ & $\begin{array}{l}\text { Major compounds: } \\
\text { a-pinene, camphene, } \beta \text {-pinene, } \beta \text {-myrcene, limonene, cineole, } \\
\text { p-cymene, camphor, bornyl acetate, } \alpha \text {-terpineol, Borneol, Verbenone }\end{array}$ & All present \\
\hline Relative density of the essential oil & 0.895 to 0.920 & 0.897 to 0.908 \\
\hline Refractive index of the essential oil & 1.464 to 1.473 & 1.465 to 1.469 \\
\hline Optical rotation of the essential oil & $\left(-5^{\circ}\right)$ to $\left(+8^{\circ}\right)$ & $\left(+6.17^{\circ}\right)$ to $\left(+7.20^{\circ}\right)$ \\
\hline Acid value of the essential oil & Maximum 1.0 & 0.33 to 0.5 \\
\hline Lavandula angustifolia & BP 2013 & BAU botanical garden \\
\hline Morphological features & $\begin{array}{l}\text { The flower has a short peduncle and consists of a bluish-grey tubular } \\
\text { calyx } 4-7 \mathrm{~mm} \text { long, and a blue bilabial corolla } 10-12 \mathrm{~mm} \text { long, } \\
\text { with the upper lip straight and bifid ( } 2 \text { large lobes) and the lower lip } \\
\text { spreading and trilobite ( } 3 \text { smaller lobes). }\end{array}$ & As mentioned \\
\hline Microscopical characteristics & $\begin{array}{l}\text { Clusters of calcium oxalate; sinuous walled calyx epidermal cells } \\
\text { containing prismatic crystals of calcium oxalate; labiate type } \\
\text { glandular trichomes; glandular trichomes; bifurcating covering } \\
\text { trichomes; spherical, hexacolpate pollen grains. }\end{array}$ & As mentioned \\
\hline Thin layer chromatography & 1,6-cineole, linalool, linalyl acetate & Present \\
\hline Foreign matter & Maximum 5\% & 1.4 to $2.1 \%$ \\
\hline Moisture content & Maximum $100 \mathrm{~mL} / \mathrm{kg}$ & 7.2 to $8.5 \%$ \\
\hline Essential oil yield & Minimum $13 \mathrm{~mL} / \mathrm{kg}$ of essential oil (anhydrous drug) & 26.7 to $32 \mathrm{~mL} / \mathrm{kg}$ \\
\hline Gas chromatography analysis of the essential oil & $\begin{array}{l}\text { Major compounds: } \\
\text { 1,8-cineole, camphor, linalool, linalyl acetate, lavandulyl acetate, } \\
\text { Lavandulol. }\end{array}$ & $\begin{array}{c}\text { Major compounds: } \alpha \text {-pinene, } \\
\beta \text {-pinene,Limonene, } 1,8 \text {-cineole, linalool, } \\
\text { Lavandulol }\end{array}$ \\
\hline Relative density of the essential oil & 0.878 to 0.892 & 0.897 to 0.908 \\
\hline Refractive index of the essential oil & 1.455 to 1.466 & 1.465 to 1.469 \\
\hline Optical rotation of the essential oil & $\left(-12.5^{\circ}\right)$ to $\left(-6.0^{\circ}\right)$ & $\left(+6.17^{\circ}\right)$ to $\left(+7.20^{\circ}\right)$ \\
\hline Acid value of the essential oil & Maximum 1.0 & 0.33 to 0.5 \\
\hline
\end{tabular}

6 revealed that the oil is composed mainly of monoterpenes. The proportions of oxygenated monoterpenes were greater than those of monoterpene hydrocarbons. As for the sesquiterpenes, they represented the minor proportion of the studied volatile oil. However, the sesquiterpene hydrocarbons were more abundant than the oxygenated sequiterpenes (Table 5). The oil also contained some aromatic hydrocarbons, aromatic ketones, aliphatic alcohols, ketones, and alkynes.

EO from (R-MR) had the highest percentage of monoterpene hydrocarbons $(35.57 \pm 0.37 \%)$ while that of (R-SP) had the lowest $(26.76 \pm 0.11 \%)$. However, REO from (R-SP) was the richest in oxygenated monoterpenes $(68.64 \pm 0.43 \%)$, while that of (R-JN) was the poorest with oxygenated monoterpenes representing $(51.91 \pm 0.05 \%)$ of the total identified components. On the other hand, REO from (R-JN) had, relatively, the greatest proportion of sesquiterpene hydrocarbons of $(11.05 \pm 0.03 \%)$. However, REO from (R-SP) recorded the smallest proportion of these compounds $(0.79 \pm 0.29 \%)$. Oxygenated sesquiterpenes were highest in REO from (R-AP) representing $(1.47 \pm 0.01 \%)$, and lowest in REO from (R-SP) representing only traces $(0.19 \pm 0.06 \%)$ of the total. In brief, REO from (R-SP) was the richest in oxygenated terpenes, and that from (R$\mathrm{JN}$ ) was the richest in terpene hydrocarbons (Table 5).

Regarding the individual components of the EO, Camphor, 1,8-Cineole and $\alpha$-Pinene were the 3 most abundant compounds identified in the 5 samples. EOs from (R-AG, R-MR and R-JN) had almost equal amounts of Camphor representing about $25 \%$ of the oil. REO from (R-SP) had 


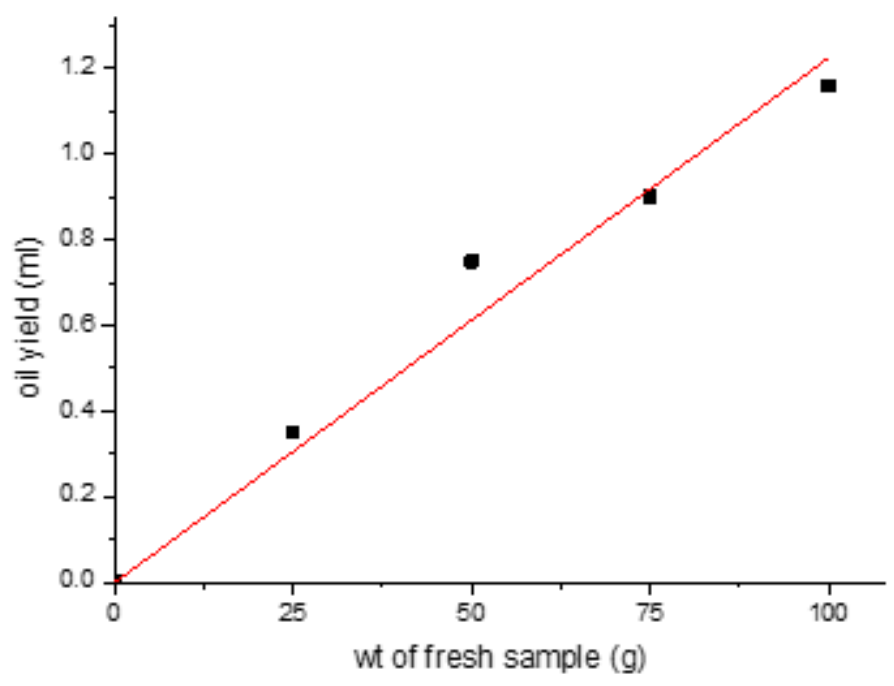

Figure 13: Calibration curve foe essential oil yield of R-MR.

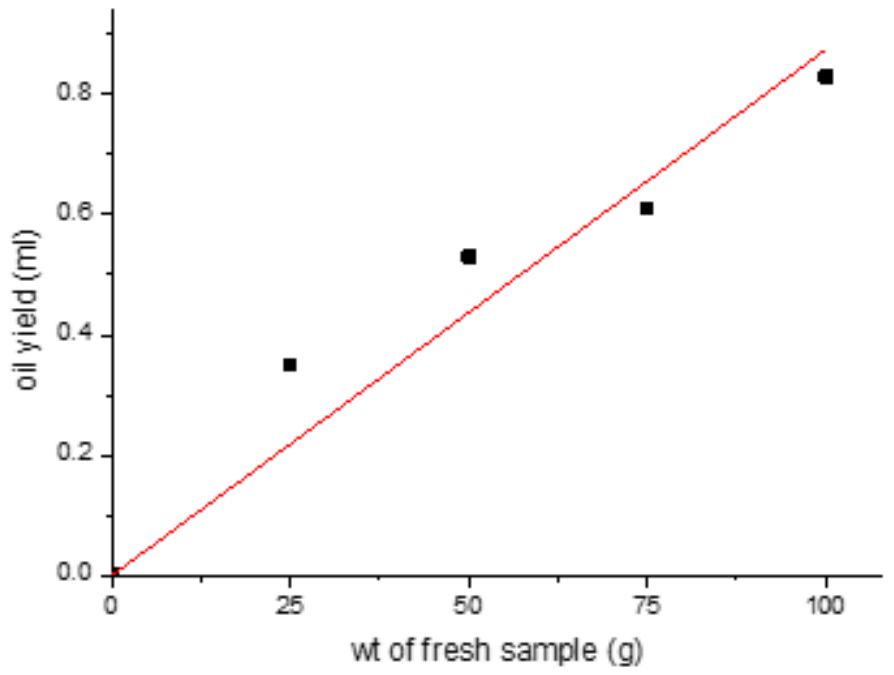

Figure 14: Calibration curve for essential oil yield of R-AP.

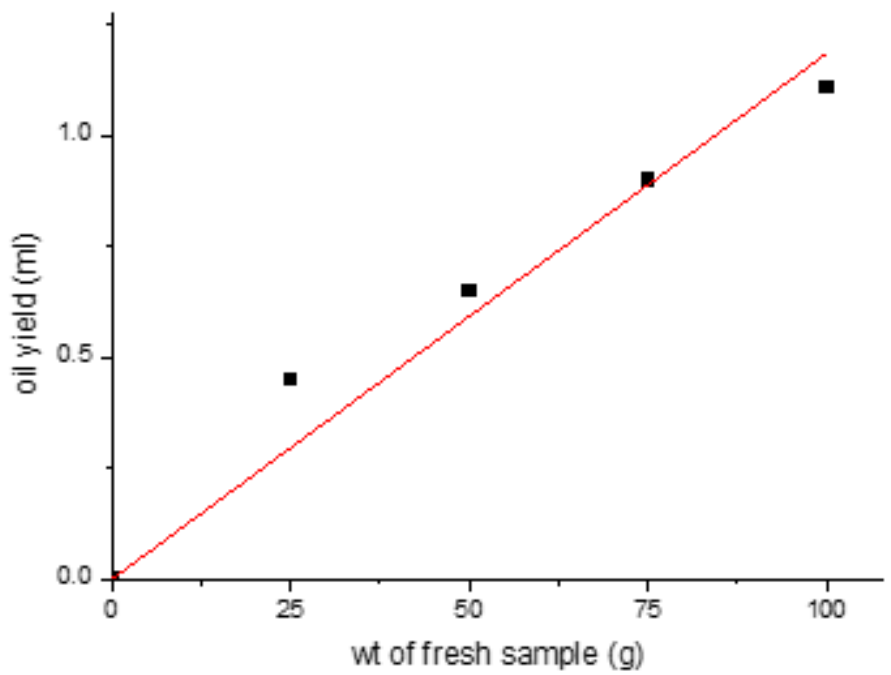

Figure 15: Calibration curve for essential oil yield of R-JN.

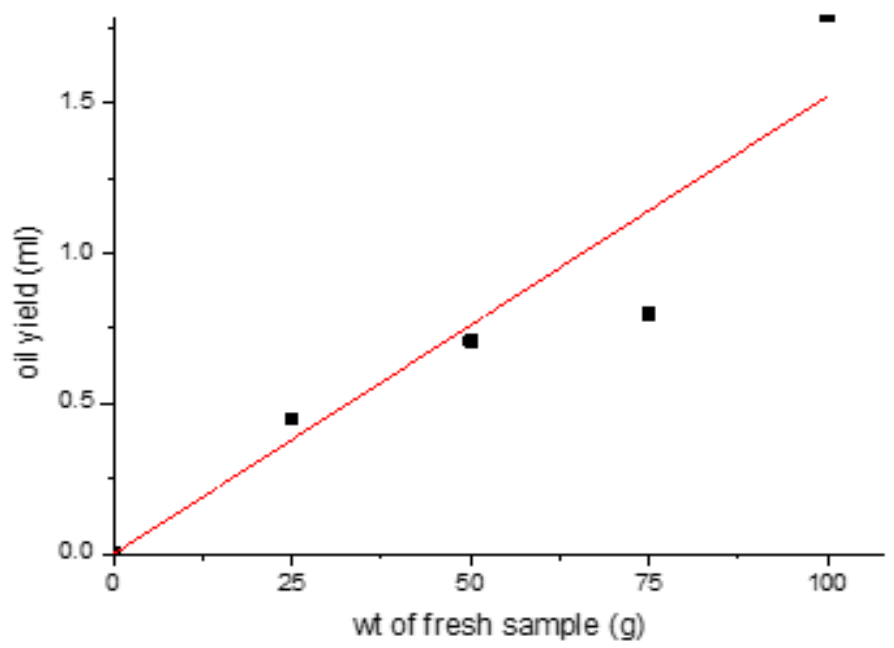

Figure 16: Calibration curve for essential oil yield of R-JN.

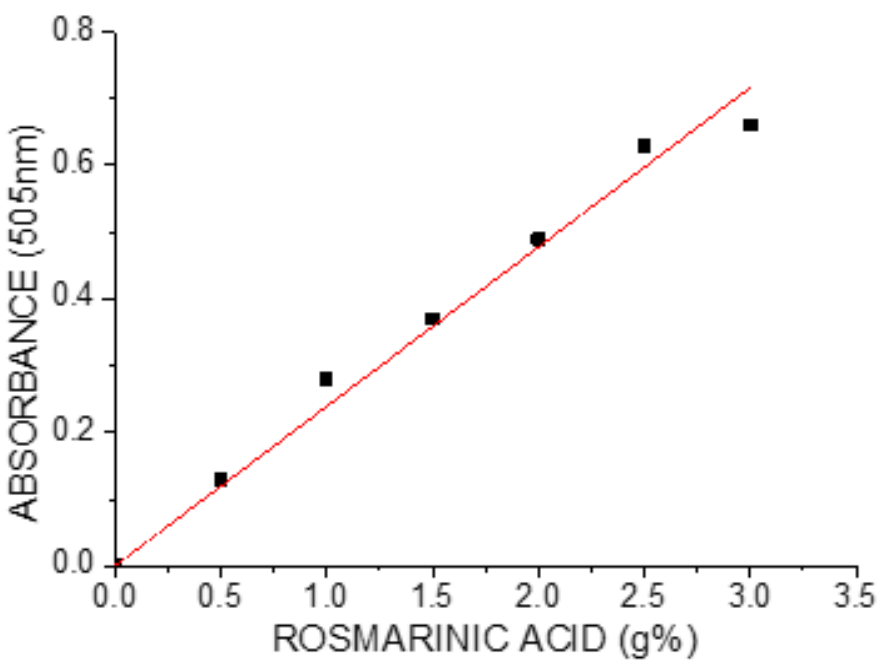

Figure 17: Calibration curve for Rosmarinic acid (standard).

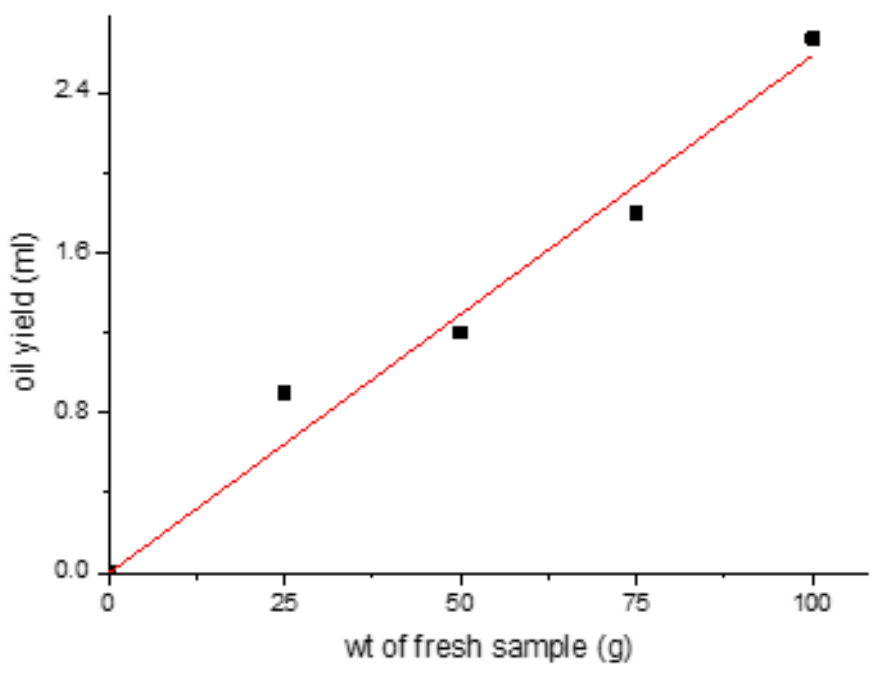

Figure 18: Calibration curve for essential oil yield of L-SP. 
the highest content of this monoterpene ketone representing (31.31 \pm $0.20 \%$ ) of the oil composition. As for REO from (R-AP), the percentage of this component was the lowest representing $(16.78 \pm 0.03 \%)$ of the total identified compounds. However 1,8-Cineole was the most abundant component of (R-AP) representing $(23.25 \pm 0.06 \%)$ of the oil (Figure 4A). It was reported that the typical REO was mainly composed of a-Pinene, 1,8-Cineole and Camphor. ${ }^{36}$ Results of the current study proved that the five samples of Rosemary contained these 3 components as the major constituents with varying percentages. According to the values of these major components, it was evident that the studied REO was

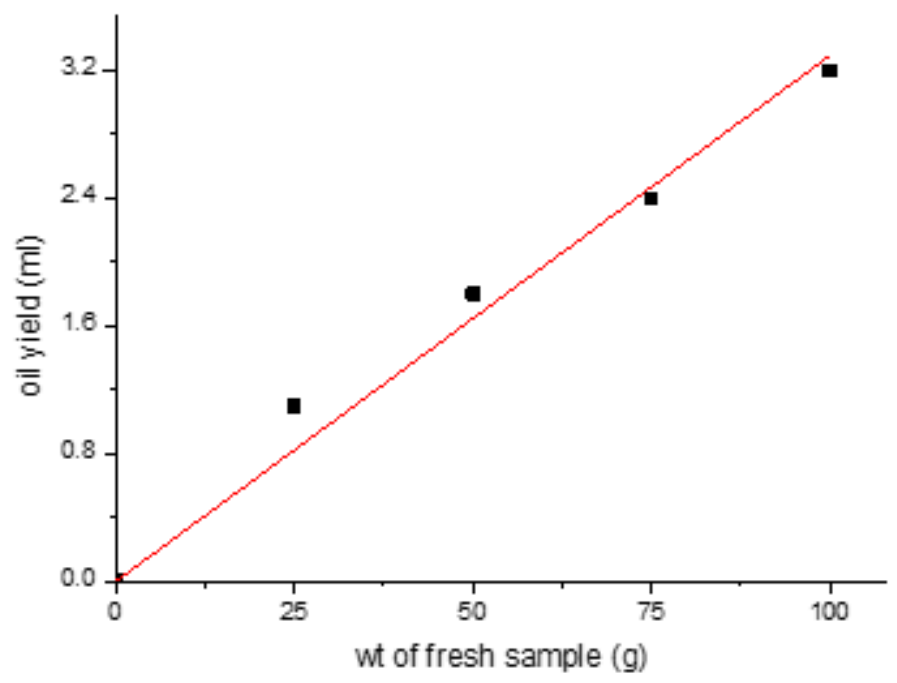

Figure 19: Calibration curve for essential oil yield of L-JL. of the Spanish chemotype. ${ }^{16}$ Other than the Spanish chemotype of REO which is characterized by 1,8-Cineole, Camphor and $\alpha$-Pinene as the major constituents with almost similar proportions of 1,8-cineole and camphor (20-30\%), the Moroccan-Tunisian chemotype is characterized by higher content of 1,8-Cineole (38-55\%). ${ }^{16,23}$

Physical properties of EOs are helpful for assuring the authenticity of EOs. Many adulterants such as synthetic EO components can lower or raise values of the physical properties of EOs. In many monographs, physical measurements of relative density, refractive index and optical rotation of an EO are required. ${ }^{37}$ The relative density of REO from the five studied samples were within the range of relative density for REO $(0.895-0.920)$ as stated by the PB 2013. Values from earlier studies were similar to values of the current study. It was reported that the relative density for REO was $0.9 .^{38}$ It was also documented that the relative density for different samples of REO was in the range of 0.8940 to $0.9120 .^{7}$ Other authors also determined the relative density of REO as $0.8887 . .^{29}$ The difference between values obtained from the literature and those from the current study could be due to the difference in the temperature at which the measurements were done. In the current study, measurements were done at $20^{\circ} \mathrm{C}$ as specified by BP,2013. However, some measurements for relative density were done at $22 \pm 2{ }^{\circ} \mathrm{C} .{ }^{39}$

The refractive indices of REO from the five studied samples were in the range $1.464-1.471$ (Table 7 ). The values were in agreement with the range of refractive index values (1.464 to 1.473) specified by the BP, 2013 for REO. These Values were also in agreement with previously reported values for refractive index of REO such as $1.465,1.4689,1.470$, and 1.465 - 1.467.7, 9, 38, 39

The optical rotation values for REO were found to be in the range of $\left(+6.17^{\circ}\right.$ to $\left.+7.20^{\circ}\right)$ as shown in (Table 7$)$. These values coincided with

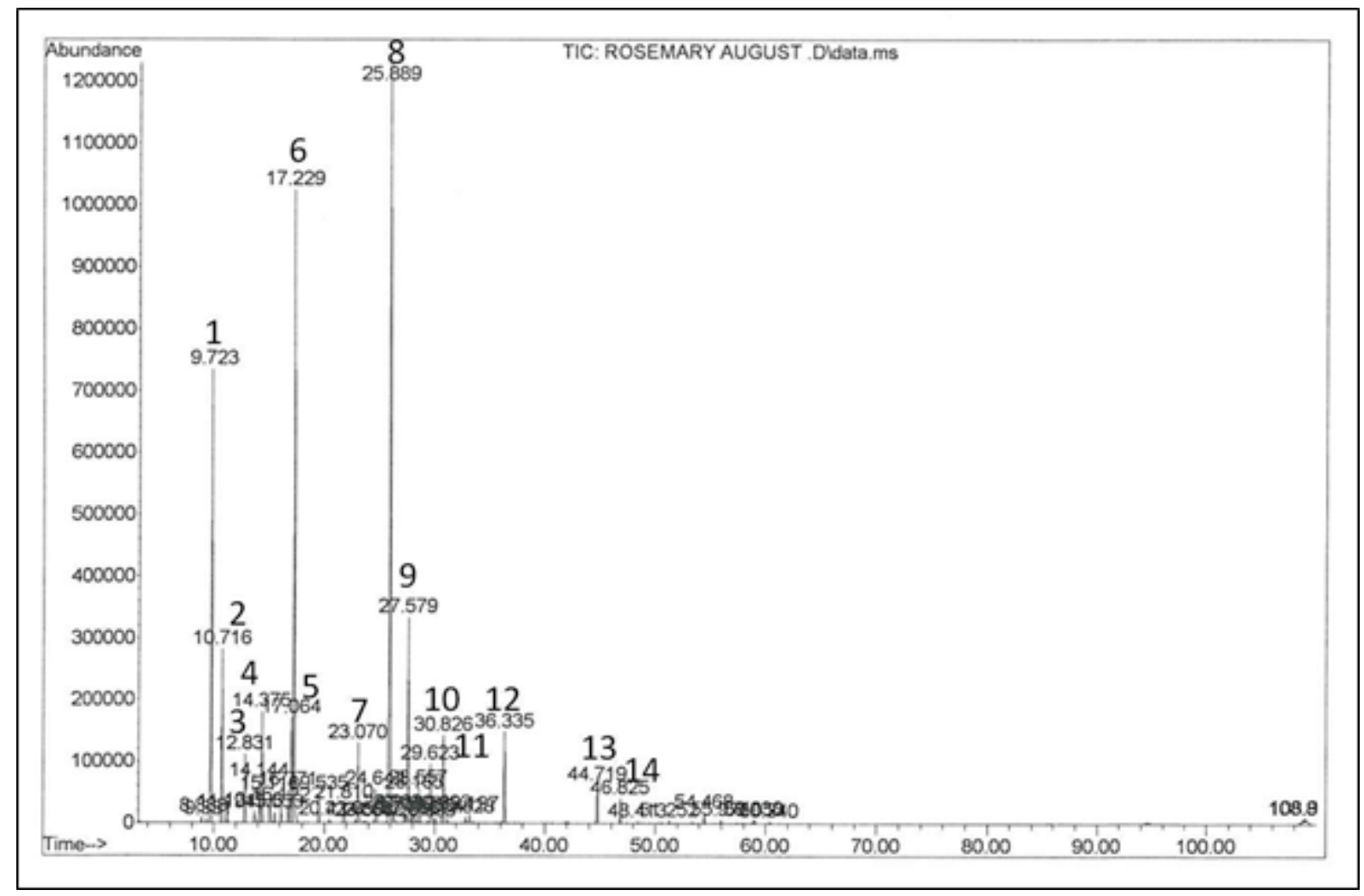

Figure 20: GC-MS chromatogram of REO from (R-AG). (1) a-Pinene; (2) Camphene; (3) $\beta$-Pinene; (4) $\beta$-Myrcene; (5) Limonene; (6) 1,8-Cineole; (7) 4-Carene; (8) Camphor; (9) Borneol; (10) Verbenone; (11) a-Terpineole; (12) Bornyl acetate; (13) $\beta$-Caryophyllene; (14) a-Caryophyllene. 


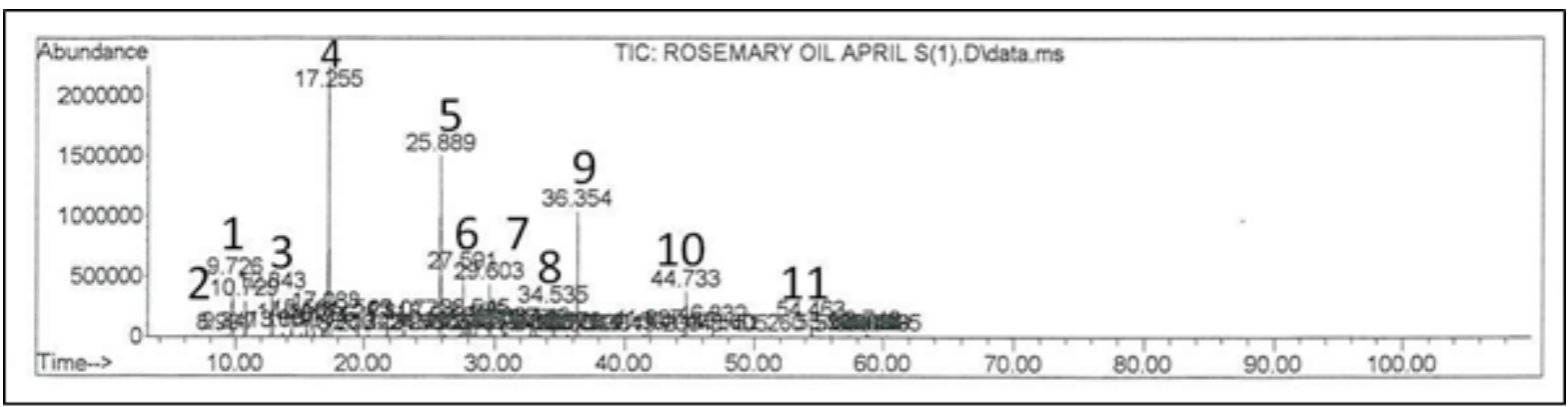

Figure 21: GC-MS chromatogram of REO from (R-AP). (1) $\alpha$-Pinene; (2) Camphene; (3) $\beta$-Pinene; (4) 1,8-Cineole; (5) Camphor; (6) Borneol; (7) a-Terpineole; (8) + $\delta 3$-Carene; (9) Bornyl acetate; (10) $\beta$-Caryophyllene; (11) Caryophyllene oxide.

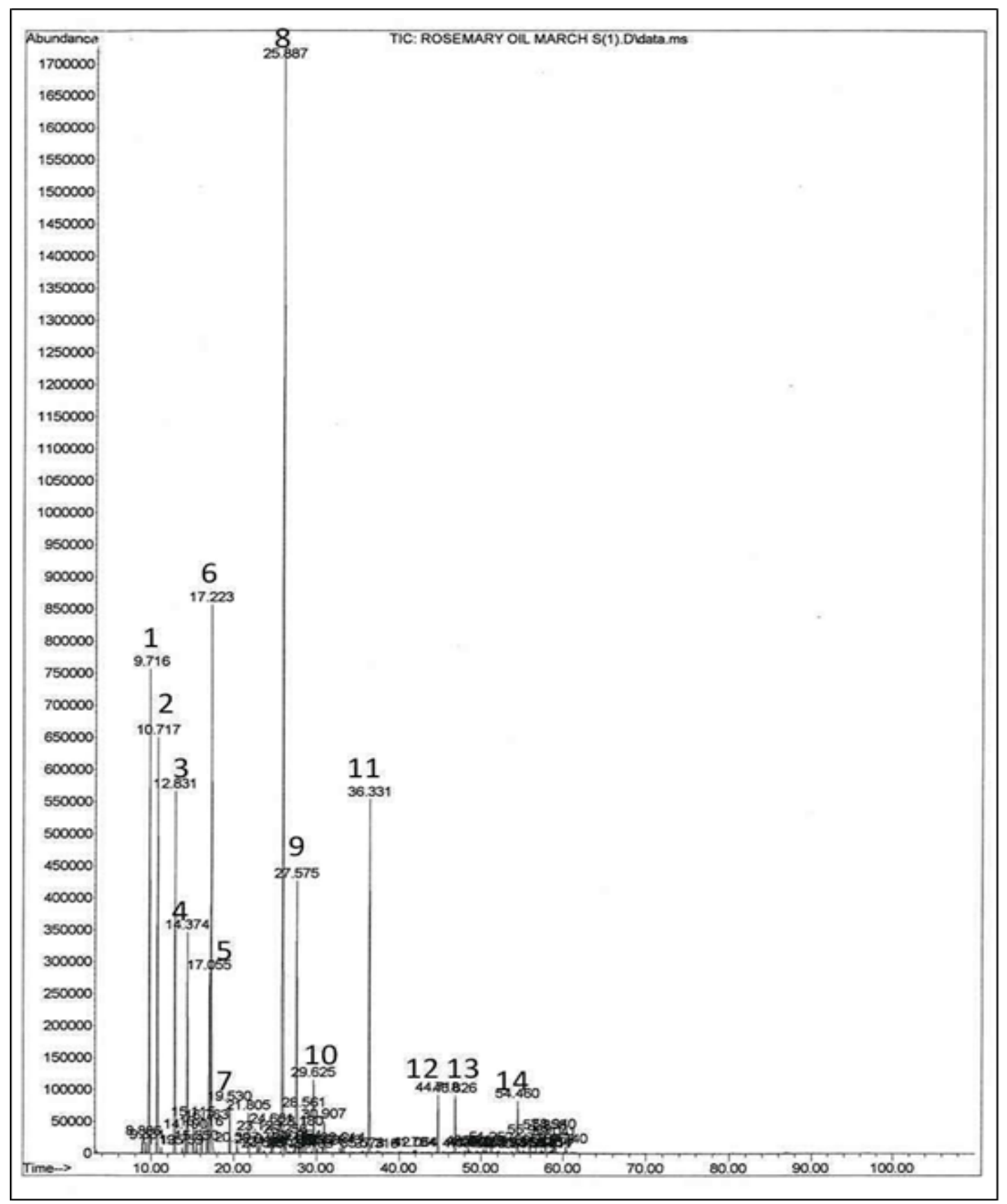

Figure 22: GC-MS chromatogram of REO from (R-MR). (1) a-Pinene; (2) Camphene; (3) $\beta$-Pinene; (4) $\beta$-Myrcene; (5) Limonene; (6) 1,8-Cineole; (7) $\alpha$-Terpinene; (8) Camphor; (9) Borneol; (10) a-Terpineole; (11) Bornyl acetate; (12) $\beta$-Caryophyllene; (13) a-Caryophyllene; (14) Caryophyllene oxide. 


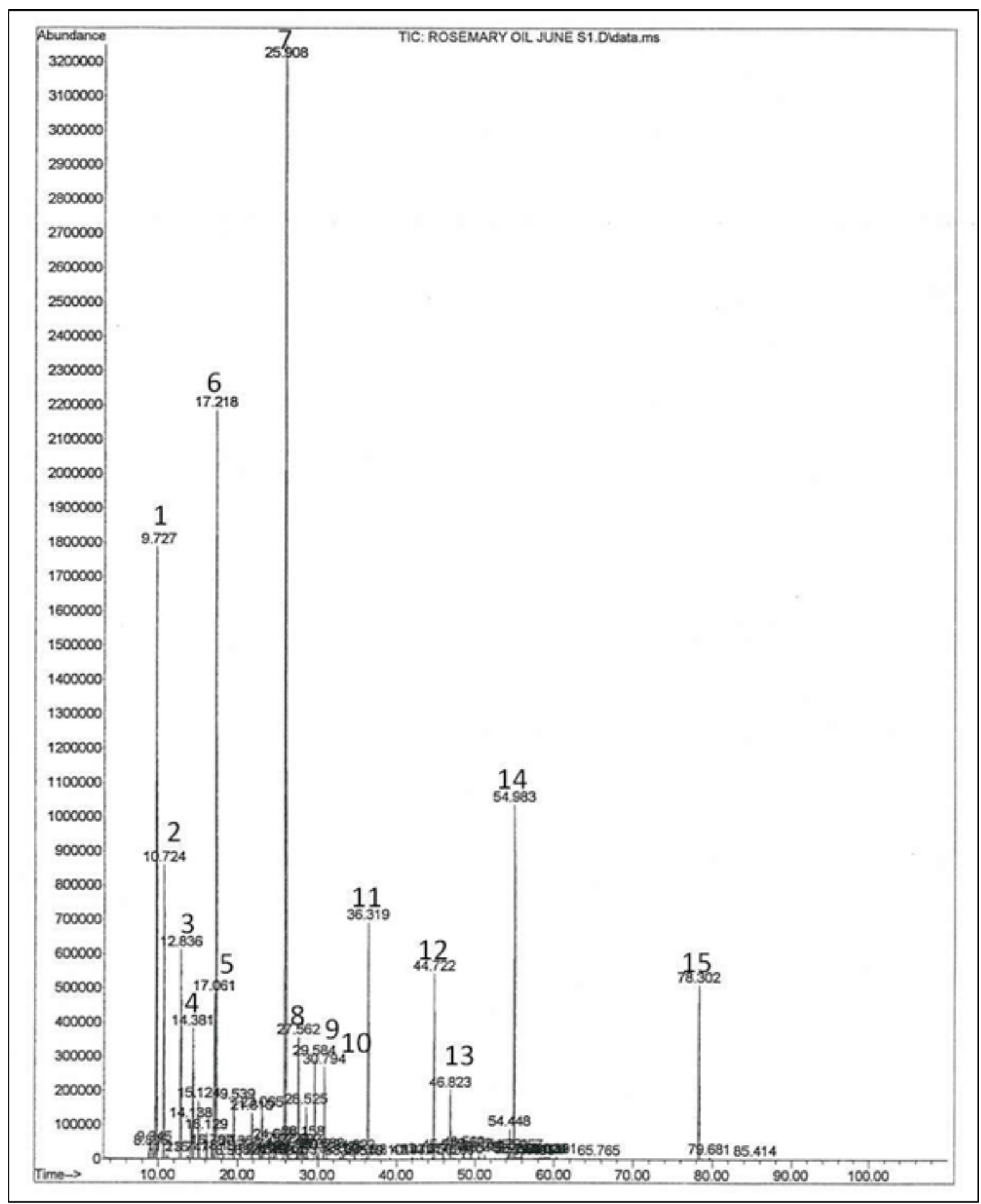

Figure 23: GC-MS chromatogram of REO from (R-JN). (1) $\alpha$-Pinene; (2) Camphene; (3) $\beta$-Pinene; (4) $\beta$-Myrcene; (5) Limonene; (6) 1,8-Cineole; (7) Camphor; (8) Borneol; (9) a-Terpineole; (10) Verbenone; (11) Bornyl acetate; (12) $\beta$-Caryophyllene; (13) a-Caryophyllene; (14) Caryophyllene oxide; (15) a-Farnesene..

the range of optical rotation for REO $\left(-5^{\circ}\right.$ to $\left.+8^{\circ}\right)$ specified in the $\mathrm{BP}$ 2013. Results from literature showed varying results. REO was reported to have an optical rotation of $0.61^{\circ}, 0.82^{\circ},+3.00^{\circ 7,38}$ and $+11.82^{\circ} .{ }^{29}$

Chemical properties for EOs include the acid value. It was less than 1 for all the tested samples, which is the maximum limit specified in the BP, 2013.

L. angustifolia (Linn.) has been reported to have biological activities. Many studies have documented its effects. Pharmacognostic studies on
L. angustifolia (Linn.) have been done previously. These included steps both for the proper identification of plant material and for the analysis of the EO. ${ }^{19}$ Both macroscopic and microscopic examinations have revealed that the morphological features of the plant material and diagnostic key elements are similar to those described in the BP 2013 (Figures 5 and 6). ${ }^{23}$

Assay of Lavender flowers for their yields of EO revealed that higher yield was obtained from L-JL (3.20 $\pm 0.59 \%)$. However, LEO yield was 


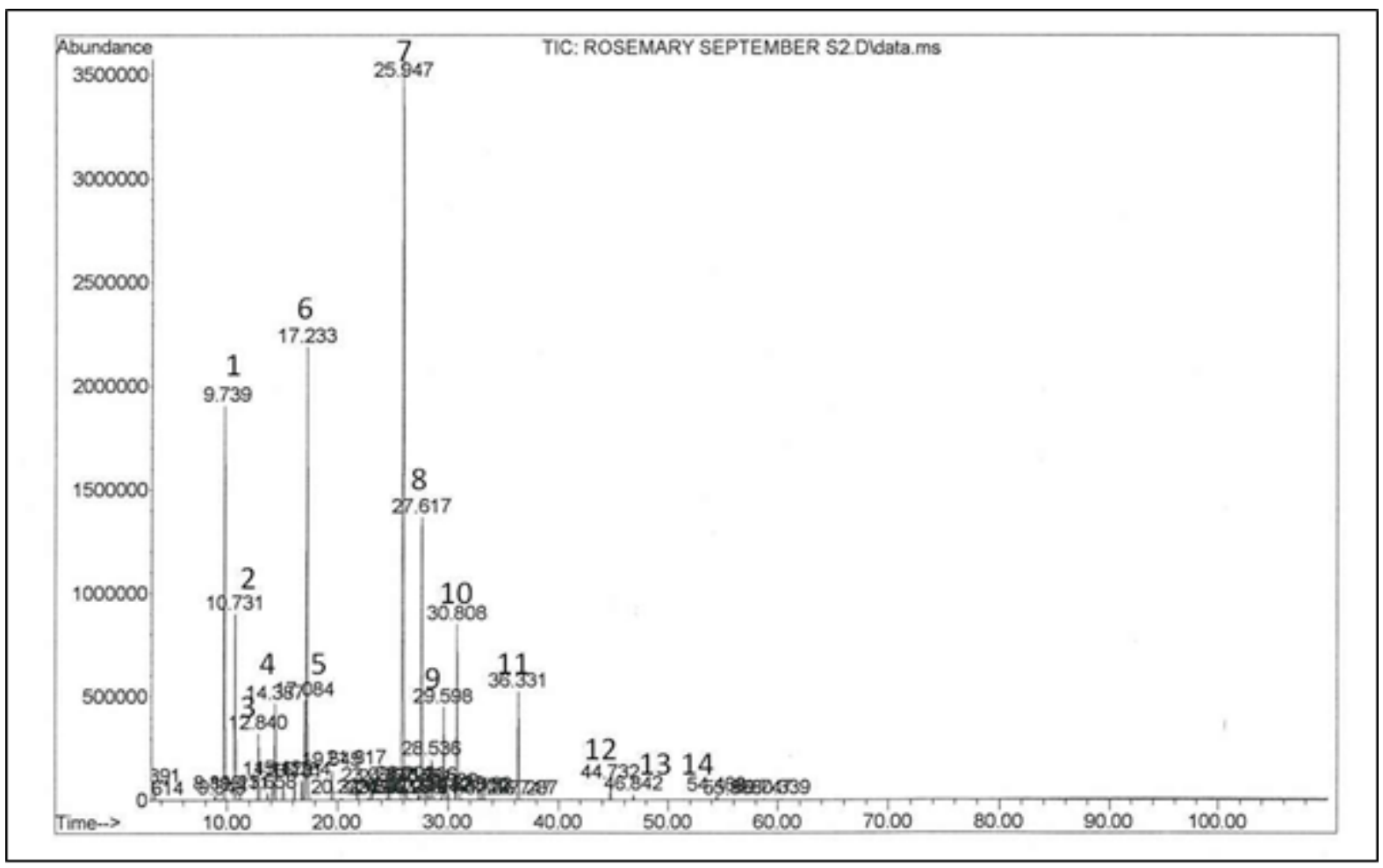

Figure 24: GC-MS chromatogram of REO from (R-SP). (1) a-Pinene; (2) Camphene; (3) $\beta$-Pinene; (4) $\beta$-Myrcene; (5) Limonene; (6) 1,8-Cineole; (7) Camphor; (8) Borneol; (9) a-Terpineole; (10) Verbenone; (11) Bornyl acetate; (12) $\beta$-Caryophyllene; (13) a-Caryophyllene; (14) Caryophyllene oxide.

$(2.67 \pm 0.53 \%)$ for L-SP (Table 8$)$. Therefore, both samples produced EO in yields greater than the minimum limit of $1.3 \%$ specified for L. angustifolia. ${ }^{23}$ Previously reported data showed variable results. For example the yield of LEO from L. angustifolia (Linn.) grown in Greece was (2.19 to $4.45 \%)^{40}$ and the yield of LEO from L. angustifolia (Linn.) grown in California was as high as $6.78 \%{ }^{41}$ These variations yield could be linked to environmental and climatic factors. ${ }^{40}$

Inspection for foreign matter in Lavender samples have shown that (LSP) and (L-JL) contained $2.1 \mathrm{~g} \%$ and $1.4 \mathrm{~g} \%$ respectively (Table 9). These values were within the limits specified by the BP 2013 for L. angustifolia in this regards. ${ }^{23}$ As for the water content, (L-SP) and (L-JL) had (7.2\%) and $(8.5 \%)$ of moisture respectively (Table 10$)$. These values were also within the specified limits. ${ }^{23}$

Thin layer chromatography of LEO from both Lavender samples showed violet zones corresponding to Linalool and 1,8-Cineole (Figure 7). These results were similar to the results described in the BP 2013. ${ }^{23}$ However, the violet zones that were supposed to show relative to Linalyl acetate were very faint and almost not apparent. This could be due to the fact that Linalyl acetate was present in trace amounts (less than $0.05 \%$ ) in LEO as proved by GC-MS analysis (Table 11).

The GC-MS analysis of the EO obtained from the two samples of Lavender revealed that the oil is composed mainly of monoterpenes. Sesquiterpenes represented only a small percentage relatively (Table 11). The oil also contained some aliphatic unsaturated hydrocarbons, and aliphatic alcohols. In both samples, oxygenated monoterpenes were present in greater amounts than monoterpene hydrocarbons. LEO from (L-JL) was richer in oxygenated monoterpenes. However, LEO from (L-SP) constituted of $3 \%$ more of monoterpene hydrocarbons than LEO from (L-JL). As for the sesquiterpenes, they only constituted a minor content in the studied LEO representing $(0.2 \%)$ in (L-SP) and about $(0.1 \%)$ in L-JL. In both samples, oxygenated sesquiterpenes were less than the hydrocarbons (Table 11). Results obtained from previous studies were similar. It was reported that the monoterpene content in LEO was more than $(90 \%)$, (87.5 \%) being oxygenated monoterpenes and $(4.4 \%)$ being monoterpene hydrocarbons. The sesquiterpene hydrocarbons were greater than the oxygenated sesquiterpenes representing (4.8 and 1.9\%) of the LEO respectively. Total monoterpenes represented about $(91.8 \%)$ of LEO while the sesquiterpene content was $(6.7 \%) .{ }^{42}$

As mentioned earlier, oxygenated compounds of LEO represented the highest proportion of the total identified compounds in the 2 samples analyzed. These compounds were mainly ethers, alcohols, and ketones. However, aldehydes and esters were present at trace amounts. Phenolics were absent. In LEO from (L-SP and L-JL), the major oxygenated compounds were of the ether type. LEO from (L-JL) was richer in ethers which represented $(71.12 \pm 0.81 \%)$ of the total. However LEO from (L$\mathrm{SP})$, constituted of higher levels of alcohols and ketones (5.73 $\pm 0.50 \%$ and $4.83 \pm 0.17 \%$ ) respectively (Table 12 ).

In this study, the major components of LEO from both samples (L-SP and L-JL) were 1,8-Cineole, Limonene, $\beta$-Pinene, Terpinolene, Linalool, Camphor, $\alpha$-Pinene and Lavandulol (Table 11).

Variations in chemical composition of LEO have been reported to be related to environmental factors. Different conditions can result in different chemotypes of the plant. ${ }^{43}$ It was also confirmed that the chemical composition of LEO was affected by diurnal harvest ${ }^{22}$, location ${ }^{22,40}$ and flowering period ${ }^{40}$ of lavender. This explains the variation in the composition of LEO from different geographical locations with subsequent emergence of different chemotypes. According to the BP 2013, the major components of LEO are Linalool (20-45\%) and Linalyl acetate (25-47 $\%$ ). Investigation of the composition of LEO from different regions of the world, have revealed that EOs of Lavender from different locations such as Greece, ${ }^{22}$ Italy, ${ }^{20,44}$ Poland ${ }^{45}$ Tunisia, ${ }^{46}$ South Africa, ${ }^{21}$ and Japan ${ }^{47}$ were characterized by comparable levels Linalool and Linalyl acetate 


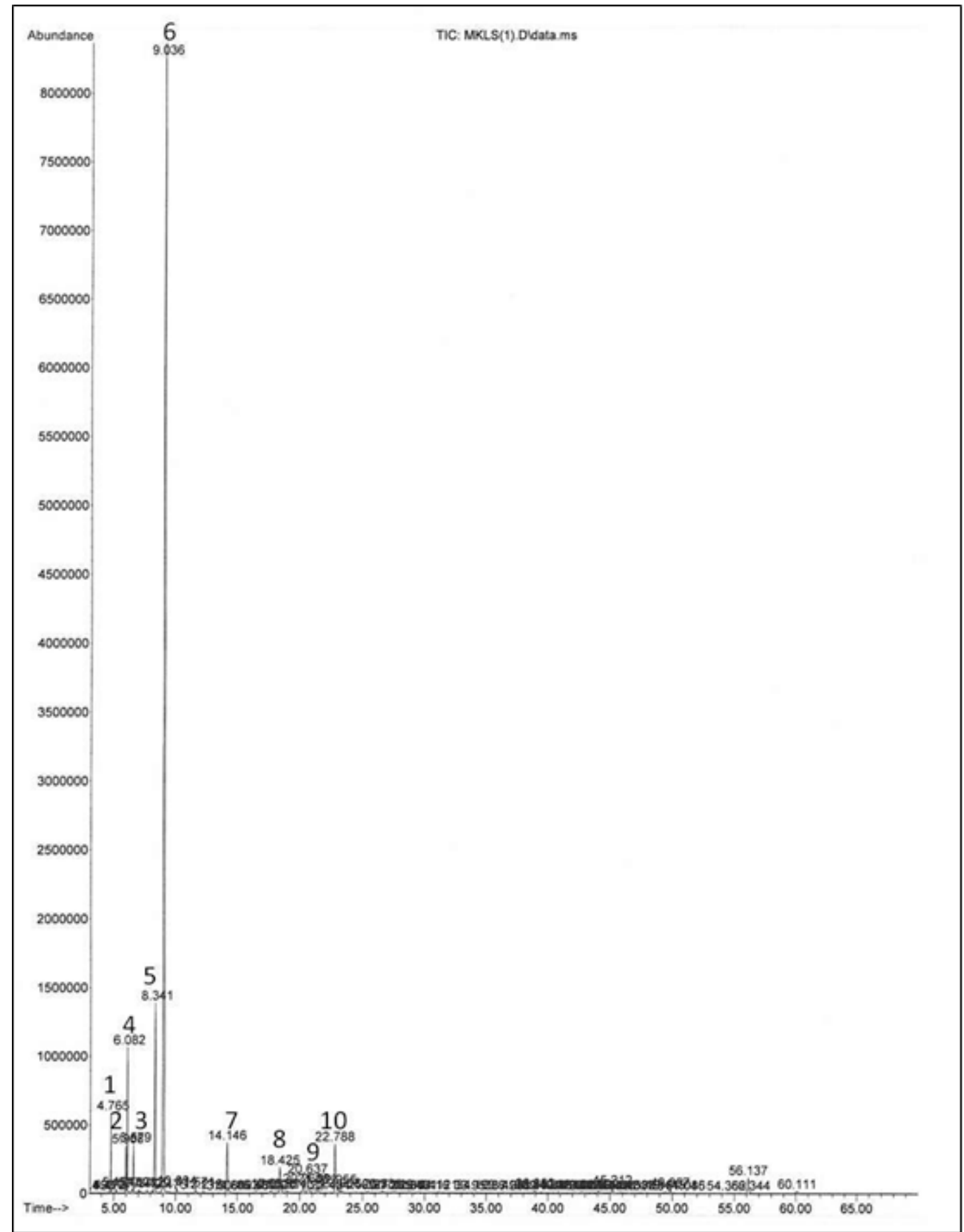

Figure 25: GC-MS chromatogram of LEO from (L-SP). (1) a-Pinene; (2) Camphene; (3) $\beta$-Phellandrene; (4) $\beta$-Pinene; (5) Limonene; (6) 1,8-Cineole; (7) Linalool; (8) Camphor; (9) Lavandulol; (10) Terpinolene.

as those indicated by the BP 2013. However, similar to results of the current study, LEO from north east Italy ${ }^{44}$ had appreciable amounts of 1,8-Cineole and camphor (3.98-10.89\% and 5.56-11.76 \% respectively) which are higher than those listed by the $\mathrm{BP}^{44}$ This is similar to what was reported previously regarding LEO from Greece which had appreciable amounts of Camphor (7.4 \%) and 1,8-Cineole (12.4\%). ${ }^{48}$ Tunisian LEO was characterized by close results. The 1,8-Cineole content was (14.1\%), and that of Camphor was (11.1\%). ${ }^{46}$ Likewise, LEO from Argentina had camphor $(8.4 \%)$ and 1,8 -Cineole $(6.8 \%) .{ }^{49}$ Similar to the results ob- tained in this study, it was reported that the major compound of LEO from Algeria was 1,8-Cineole (29.4\%). Similar to the results of the current study also, LEO from Algeria had a low level of linalool of (1.1\%)..$^{50}$ In terms of Limonene, it was reported that LEO from North East Italy had a (1.1 to 2.36$) \%$ of Limonene, ${ }^{20}$ which was higher than the range listed in the BP 2013. Similarly, results of the current study had higher values of Limonene $(8.58 \pm 0.06-9.11 \pm 0.33 \%)$. Relative to the high content of 1,8 -Cineole $(64.99 \pm 0.92$ and $71.08 \pm 0.86 \%)$ in the two tested samples (Table 11), LEO investigated in this study is of the 1,8-Cineole 


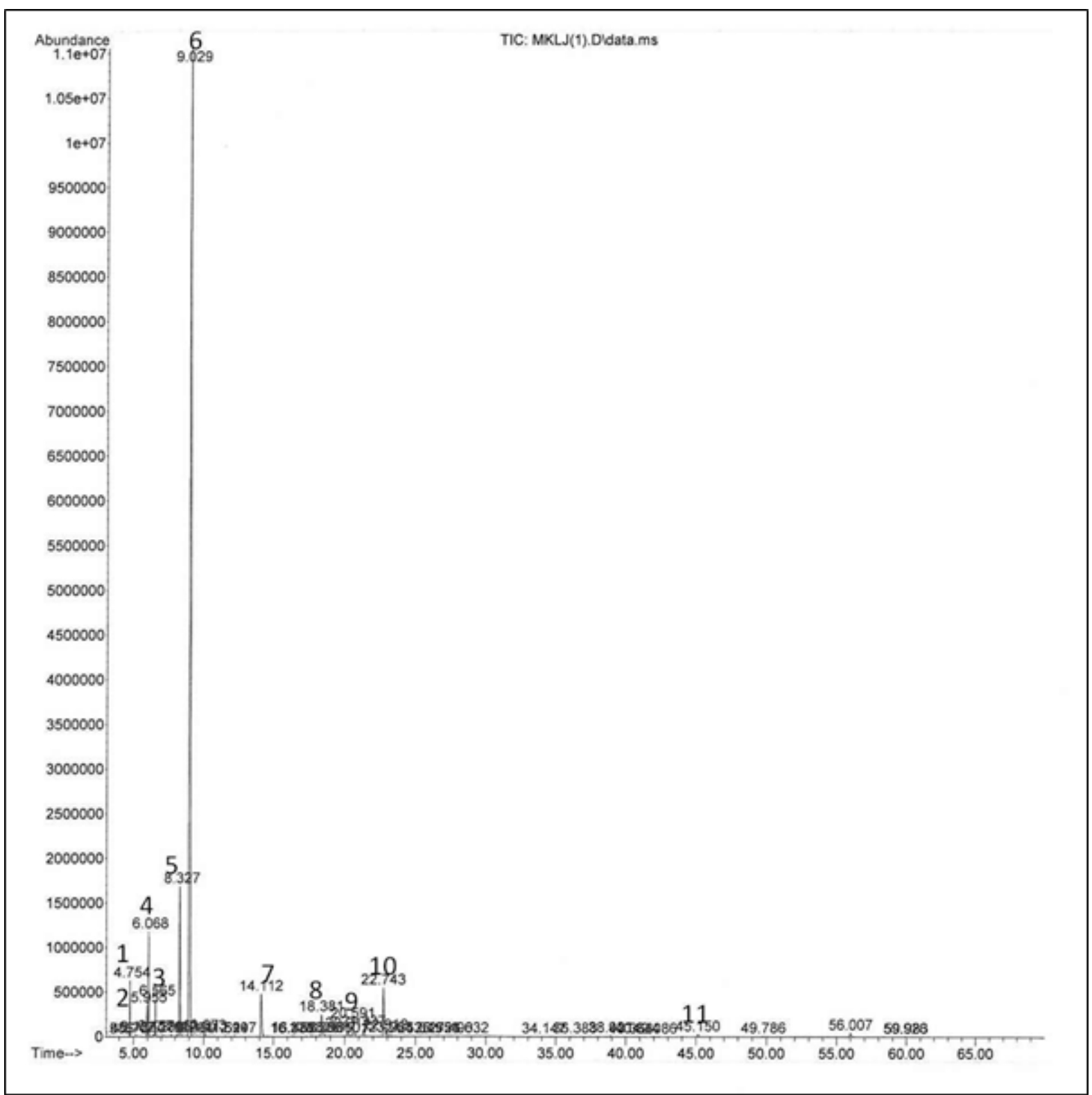

Figure 26: . GC-MS chromatogram of LEO from (L-JL). (1) a-Pinene; (2) Camphene; (3) $\beta$-Phellandrene; (4) $\beta$-Pinene; (5) Limonene; (6) 1,8-Cineole; (7) Linalool; (8) Camphor; (9) Lavandulol; (10) Terpinolene; (11) allo-Ocimene.

chemotype. Seasonal variations affect the final composition of the EO. Variations in the chemical composition of LEO from the two tested samples could be linked to seasonal variations. ${ }^{22}$

The values of relative density for LEO from (L-SP) and (L-JL) were found as 0.892 and 0.889 respectively (Table 13 ). These values coincided with the range of relative density for LEO ( 0.878 to 0.892$)$ specified in the BP, 2013. The refractive index values for LEO from (L-SP) and (L-JL) were found as 1.459 and 1.464 respectively (Table 13). According to BP, 2013, the range of refractive index for LEO is 1.455 to 1.466 . Therefore, results for LEO from (L-SP) and (L-JL) matched those mentioned in BP. In addition, results from the literature involving physiochemical properties of LEO had very close or even identical values as results of the current study. It was reported that the relative density and refractive index of LEO were 0.882 and 1.459 respectively. ${ }^{47}$ The optical rotation values for LEO from (L-SP) and (L-JL) were within the range of optical rotation for LEO $\left(-12.5^{\circ}\right.$ to $\left.-6.0^{\circ}\right)$ specified in the BP, 2013 (Table 13). For both samples, the acid value for LEO was less than 1 , matching the limit stated by the BP, $2013 .^{23}$

Rosemary has been reported to be one of the aromatic plants having high antioxidant activity. ${ }^{7}$ Correlations between the chemical compositions of studied $R$. officinalis (Linn.) essential oils and their DPPH radical scavenging capacity have been reported. ${ }^{7,16,51}$ For example, fractions of REO containing ethers and alcohols recorded the highest antioxidant activity $^{7}$ In this research, similar results were obtained. Comparison between REO from the 5 test samples for classes of oxygenated compounds present in the oil was demonstrated in Table 6. REO from (R-AP) presented the highest content of alcohols and ethers. On the other hand, REO from (R-JN) had the lowest content of alcohol and Ethers. The highest antioxidant activity was recorded with REO from (R-AP) as demonstrated by its lowest $\mathrm{IC}_{50}(9.65 \pm 1.03 \mu \mathrm{l})$, and the lowest antioxidant activity was recorded with REO from (R-JN) as demonstrated by its highest $\mathrm{IC}_{50}(17.1 \pm$ $0.29 \mu \mathrm{l})$. REO from $(\mathrm{R}-\mathrm{AG})$ and $(\mathrm{R}-\mathrm{SP})$ recorded $\mathrm{IC}_{50}$ values higher than that of REO from (R-AP) and lower than that of REO from (R-JN). This 
result could also be linked to their alcohol-ether contents. Alcohols and ethers represented about (29\%) and (28\%) of REO from (R-AG) and (R$\mathrm{SP})$ respectively. REO from (R-MR) represented an exception for linking the antioxidant activity with the alcohol and ether content of REO. The alcohol-ether content of REO from (R-MR) was the second lowest as (about $22 \%$ ) but it had the second highest antioxidant activity $\left(\mathrm{IC}_{50}\right.$ of $10.83 \pm 0.38 \mu \mathrm{L}$ ). The antioxidant activity of REO has been linked to the oil's content of Myrcene and a-Pinene. Myrcene-rich REO showed higher antioxidant activity than other chemotypes of REO. ${ }^{16}$ Moreover, the antioxidant activity of REO was linked to the oil's content of the monoterpene ether 1,8-Cineole and the monoterpene hydrocarbons Myrcene and $\beta$-Pinene. ${ }^{51}$

The ability of both Myrcene and $\beta$-Pinene to scavenge the DPPH free radical has been demonstrated ${ }^{52}$ It was also reported that Myrcene protected against the genotoxic effect of oxygen reactive species both in bacterial and human cells. ${ }^{53}$ In vivo peroxidation assay for testing the antioxidant effects of Myrcene in rats liver have confirmed the antioxidant potential of this monoterpene..$^{54}$ Hence, REO from (R-MR) attained second highest antioxidant activity relative to REO from other rosemary samples due to its highest content of these 2 monoterpene hydrocarbons $\beta$-Pinene $(6.99 \pm 0.05 \%)$ and Myrcene $(4.24 \pm 0.03 \%)$ among all other REO from Rosemary samples (Figure 3 B-D).

The essential oils obtained from various Lavandula species have been tested for their antioxidant potentials. ${ }^{49,55}$ In the current study, LEO from (L-SP) showed superior antioxidant activity over LEO from (L-JL) in the DPPH assay (Table 15). The major components of LEO from both samples were oxygenated monoterpenes that represented $77.56 \pm 0.09 \%$ of LEO from (L-SP) and $72.72 \pm 1.3 \%$ of LEO from (L-JL). As for the monoterpene hydrocarbons, they constituted the minor fraction of LEO from $(\mathrm{L}-\mathrm{SP})$ and $(\mathrm{L}-\mathrm{JL})$ representing $(21.05 \pm 1.09$ and $18.56 \pm 0.27 \%)$ respectively. Therefore, LEO from (L-SP) was about 3\% richer in monoterpene hydrocarbons than LEO from (L-JL) (Table 11). This could explain the stronger antioxidant activity of (L-SP). It was previously reported that the antioxidant activity of EOs was dependent not only on the major components but also on the minor ones..$^{51,56}$ Moreover, monoterpene hydrocarbons were shown to impart significant antioxidant activity to essential oils by acting as radical scavenging agents. ${ }^{57}$ The antioxidant activity of EO from Lavandula species was attributed to the presence of monoterpene hydrocarbons. ${ }^{55,58}$ For example, essential oil from L. stoechas was linked to the presence of a-Pinene and Limonene. ${ }^{55}$ Similarly, the antioxidant activity of essential oil from $L$. angustifolia was attributed to the presence of Camphene, Limonene, Ocimene, Terpinene, $\alpha$-Pinene and $\beta$-Pinene. ${ }^{58}$ Moreover, $\alpha$-Pinene and Limonene rich essential oil prevented against lipid peroxidation in vitro and improved the ability of yeast cells to adapt to reactive oxygen species. ${ }^{59}$ The scavenging effect of $\beta$-Pinene and Limonene and their ability to protect deoxyribose against degradation by free radicals have been demonstrated. ${ }^{59}$ In the current study, the percentages of these compounds were higher in LEO from (L-SP). For example, $\beta$-Pinene represented $(4.65 \pm 0.48 \%)$ of LEO from (L-SP) and (3.83 $\pm 0.24 \%)$ of LEO from (L-JL). $\alpha$-Pinene and Limonene levels were also higher in LEO from (L-SP). It was also reported that oxygenated monoterpenes acted as radical scavenging agents. ${ }^{57}$ Allylic alcohols such as Linalool possessed appreciable antioxidant activity. ${ }^{55}$ In this study, allylic alcohols such as Myrtenol and Linalool levels were higher in LEO from (L-SP) than LEO from (L-LJ) as shown in (Table 11). Diabetes mellitus is one of the most widely spread endocrine disorders. It affects about $5 \%$ of world's population. It is estimated that more than 300 million adults will be diabetic the next decade. ${ }^{27}$ Global expenditure on the treatment of diabetes and its accompanying complications such as hyperlipidemia and hypertension, ${ }^{8}$ could reach US \$ trillion annually ${ }^{60}$ It was reported that free radicals generated by hyperglyce- mia, mediate oxidative stress which contributes in the progression of diabetes as well as its complications. ${ }^{27}$ Moreover, pancreatic $\beta$-cells have low antioxidant capacity since their antioxidant enzyme levels are low relative to other tissues. ${ }^{8}$ Therefore, the interest in antioxidants use for diabetes has increased. Their ability to reduce oxidative damage in diabetes has been demonstrated. ${ }^{33,61,62} R$. officinalis (Rosemary) has been examined for its antioxidant potential and is now recognized as one of medicinal plant species with the highest antioxidant activity. ${ }^{8}$ Moreover, in folk medicine, Rosemary is one of the plants used to combat DM in Lebanon. The phenolic contents of Rosemary have been reported to have antidiabetic potentials. ${ }^{8,33}$ Few results, however, were reported regarding the use of REO as an antidiabetic agent. ${ }^{18}$ In this study, various doses of the REO, obtained from (R-AP), were studied for their acute effects in alloxan-diabetic animals. The choice of REO from (R-AP) was based on the fact that it showed the highest antioxidant activity among the tested samples. REO at all doses showed a significant effect, when compared to the control after $6 \mathrm{~h}$ (Table 16). REO, at the dose of $110 \mathrm{mg} / \mathrm{kg}$ was the most effective dose on blood glucose of hyperglycemic mice. The subacute effects of the three doses of REO were determined (Table 17). The blood glucose levels of diabetic control mice were significantly higher than those of the control mice during the experiment period. In alloxaninduced diabetic mice, REO at all doses showed a significant effect. The highest reduction in blood glucose with REO was observed with a dose of $110 \mathrm{mg} / \mathrm{kg}$.

\section{CONCLUSION}

The chemical composition of EOs from Rosemary and Lavender grown in Lebanon showed variations in their components relative to time of collection. This was also reflected in the variation in the antioxidant activity of the oils obtained from samples collected at different times of the year. The highest antioxidant activity for Rosemary was attained by the volatile oil obtained from the flowering plants collected in April (spring season). As for Lavender, the highest antioxidant activity was attained by the volatile oil obtained from flowering plants collected in September (early fall). Testing Rosemary oil that showed the highest antioxidant activity for its in vivo antidiabetic effect using alloxan-induced diabetic mice, revealed significant lowering in blood glucose level at the dose of $110 \mathrm{mg} / \mathrm{kg}$. At this dose Rosemary EO was effective in lowering blood glucose level in diabetic mouse model up to $58 \%$ when compared to the control. Moreover, the Spectrophotometric analysis of Rosemary extract for the total hydroxycinnamic acids calculated as Rosmarinic acid showed values that are similar and even higher than values obtained for Rosemary collected from other regions of the world. As for the Pharmacognostic screening, both plant species and their EOs fulfilled most of the standards specified by the British Pharmacopeia 2013 (Table 18).

Summary: Monographs designed for Rosmarinus officinalis (Linn.) and Lavandula angustifolia (Linn.) provided a proof that these cultivated species at the Botanical garden of Beirut Arab University fulfill the international standards specified by the BP 2013 and WHO. The antioxidant potential of their essential oils has been demonstrated. Rosemary was proven to have antidiabetic potential.

\section{CONFLICTS OF INTEREST}

There are no conflicts of interest.

\section{ABBREVIATION}

REO: Rosmarinus officinalis (Linn.) essential oil; LEO: Lavandula angustifolia (Linn.) essential oil; TLC: thin layer chromatography; DPPH: 2,2-diphenyl-1-picrylhydrazyl; SD: standard deviation; SEM: standard error of the mean. 


\section{REFERENCES}

1. Zhang JB. Shang WH, Li X, and Ernst E, Quality of herbal medicines: challenges and solutions. Complement Ther Med, 2012;20(1-2):100-6. https://doi. org/10.1016/j.ctim.2011.09.004; PMid:22305255.

2. Cepae BA. WHO monographs on selected medicinal plants. 1999, Geneva: World Health Organization.

3. Murray V and Shaw D, WHO Monographs on Selected Medicinal Plants, Volume 1. Health and Hygiene, 2000;21(3):129.

4. Al-Arifi MN. Availability and needs of herbal medicinal information resources at community pharmacy, Riyadh region, Saudi Arabia. Saudi Pharm J, 2013;21(4):351-60. https://doi.org/10.1016/j.jsps.2012.11.004; PMid:24227954 PMCid:PMC3824944

5. Wiesner $\mathrm{J}$ and Knoss W, Future visions for traditional and herbal medicina products-a global practice for evaluation and regulation? J Ethnopharmacol, 2014;158:516-8. https://doi.org/10.1016/j.jep.2014.08.015; PMid:25152297.

6. Farnsworth NR, Fong HHS, and Mahady GB, WHO monographs on selected medicinal plants R. Tsai and D. Hermann Garden, Editors. 2009;284-308.

7. Beretta GR. Facino ARM, and Gelmini F, An analytical and theoretical approach for the profiling of the antioxidant activity of essential oils: The case of Rosmarinus officinalis L. Journal of Pharmaceutical and Biomedical Analysis, 2011;55(5):1255-64. https://doi.org/10.1016/j.jpba.2011.03.026; PMid:21511423.

8. Bakırel T, Bakırel U, Keles OU, Ülgen SG, and Yardibi H. In vivo assessment of antidiabetic and antioxidant activities of rosemary (Rosmarinus officinalis) in alloxan-diabetic rabbits. Journal of ethnopharmacology, 2008;116(1):64-73. https://doi.org/10.1016/j.jep.2007.10.039; PMid:18063331.

9. Ribeiro-Santos R, Carvalho-Costa D, Cavaleiro C, Costa HS, Albuquerque TG, Castilho MC, et al., A novel insight on an ancient aromatic plant: The rosemary (Rosmarinus officinalis L.). Trends in Food Science \& Technology, 2015;45(2):35568. https://doi.org/10.1016/j.tifs.2015.07.015.

10. Zaouali $Y$, BouzaineT, and Boussaid M, Essential oils composition in two Rosmarinus officinalis $L$. varieties and incidence for antimicrobial and antioxidant activities. Food and Chemical Toxicology, 2010;48(11):3144-52. https://doi. org/10.1016/j.fct.2010.08.010; PMid:20728499.

11. Marc EB, Nelly A, Annick DD, and Frederic D, Plants used as remedies antirheumatic and antineuralgic in the traditional medicine of Lebanon. Journal of ethnopharmacology, 2008;120(3):315-34. https://doi.org/10.1016/j.jep.2008.08.024; PMid:18809483

12. Martínez AL, González-Trujano ME, Pellicer F, López-Mu-oz FJ, and Navarrete A. Antinociceptive Effect and GC/MS analysis of Rosmarinus officinalis L. essential oil from its aerial parts. Planta Med, 2009;75(05):508-11. https://doi. org/10.1055/s-0029-1185319; PMid:19184968.

13. Peng Y, Yuan J, Liu F, and Ye J. Determination of active components in rosemary by capillary electrophoresis with electrochemical detection. Journal of Pharmaceutical and Biomedical Analysis, 2005;39(3-4):431-7. https://doi.org/10.1016/j. jpba.2005.03.033; PMid:15925471.

14. Amaral GP, de Carvalho NR, Barcelos RP, Dobrachinski F, Portella, da Silva MH, et al., Protective action of ethanolic extract of Rosmarinus officinalis L. in gastric ulcer prevention induced by ethanol in rats. Food and Chemical Toxicology, 2013;55:48-55. https://doi.org/10.1016/j.fct.2012.12.038; PMid:23279841.

15. Erkan N, Ayranci G, and Ayranci E, Antioxidant activities of rosemary (Rosmarinus Officinalis L.) extract, blackseed (Nigella sativa L.) essential oil, carnosic acid, rosmarinic acid and sesamol. Food Chemistry, 2008;110(1):76-82. https:// doi.org/10.1016/j.foodchem.2008.01.058; PMid:26050168.

16. Ojeda-Sana AM, van Baren CM, Elechosa MA, Juárez MA, Moreno S. New insights into antibacterial and antioxidant activities of rosemary essential oils and their main components. Food Control. 2013;31(1):189-95. https://doi. org/10.1016/j.foodcont.2012.09.022.

17. Lemos MF, Lemos MF, Pacheco HP, Endringer DC, Scherer R. Seasonality modifies rosemary's composition and biological activity. Industrial Crops and Products. 2015;31;70:41-7. https://doi.org/10.1016/j.indcrop.2015.02.062.

18. Abu-Al-Basal MA. Healing potential of Rosmarinus officinalis $L$. on full-thickness excision cutaneous wounds in alloxan-induced-diabetic BALB/c mice. Journal of ethnopharmacology. 2010;15;131(2):443-50.

19. Farnsworth NR, Fong HSS, and Mahady GB. WHO monographs on selected medicinal plants, R. Tsai and D. Hermann Garden, Editors. 2007, World Health Organization Geneva. p. 219-228.

20. Evandri MG, Battinelli L, Daniele C, Mastrangelo S, Bolle P, Mazzanti G. The antimutagenic activity of Lavandula angustifolia (lavender) essential oil in the bacterial reverse mutation assay. Food and chemical toxicology. 2005;30;43(9):1381-7.

21. de Rapper S, Kamatou G, Viljoen A, and Vuuren SV, The in vitro antimicrobial activity of Lavandula angustifolia essential oil in combination with other aromatherapeutic oils. Evidence-Based Complementary and Alternative Medicine 2013. 2013.

22. Hassiotis CN, Lazari DM, Vlachonasios KE, The effects of habitat type and diurnal harvest on essential oil yield and composition of Lavandula angustifolia Mill. Fresenius Environmental Bulletin, 2010;19(8):1491-8.

23. British pharmacopoeia. London, Her Majesty's Stationery Office, 2013.

24. Rasooli I, Fakoor MH, Yadegarinia D, Gachkar L, Allameh A, and Rezaei MB,
Antimycotoxigenic characteristics of Rosmarinus officinalis and Trachyspermum copticum L. essential oils. International Journal of Food Microbiology. 2008;122(1-2):135-9. https://doi.org/10.1016/j.ijfoodmicro.2007.11.048; PMid:18190993.

25. Szumny A, Figiel A, Gutiérrez-Ortíz A, and Carbonell-Barrachina AA. Composition of rosemary essential oil (Rosmarinus officinalis) as affected by drying method. Journal of Food Engineering, 2010;97(2):253-60. https://doi. org/10.1016/j.jfoodeng.2009.10.019.

26. Raafat KM, Jassar H, Aboul-Ela M, and El-Lakany A, Protective effects of Origanum majorana $L$. against neurodegeneration: fingerprinting, isolation and in vivo glycine receptors behavioral model. International Journal of Phytomedicine, 2013;5(1):46.

27. Raafat K, Aboul-Ela M, and El-Lakany A. Alloxan-induced diabetic thermal hyperalgesia, prophylaxis and phytotherapeutic effects of Rheum ribes $L$. in mouse model. Archives of pharmacal research, 2014:1-10. https://doi.org/10.1007/ s12272-014-0372-y.

28. Raafat K, Boukhary R, Aboul-Ela M, El-Lakany A. Endogenous Lebanese plants treating diabetes and related complications. Natural Products Chemistry \& Research. 2013; 24;2013.

29. Atti-Santos AC, M Rossato, Pauletti GF, Rota LD, Rech JC, Pansera, et al., Physico-chemical evaluation of Rosmarinus officinalis L. essential oils. Brazilian Archives of Biology and Technology, 2005;48(6):1035-9. https://doi.org/10.1590/ S1516-89132005000800020.

30. Bomfim DSN, Nakassugi LP, Oliveira JFP, Kohiyama CY, Mossini SAG, Grespan $\mathrm{R}$, et al., Antifungal activity and inhibition of fumonisin production by Rosmarinus officinalis L. essential oil in Fusarium verticillioides (Sacc.) Nirenberg. Food Chemistry, 2015;166:330-6. https://doi.org/10.1016/j.foodchem.2014.06.019; PMid:25053064.

31. Jackson BP, and Snowdon DW, Atlas of microscopy of medicinal plants, culinary herbs and spices. 1990: Belhaven Press.

32. Petersen M, Abdullah Y, Benner J, Eberle D, Gehlen K, Hücherig S, et al., Evolution of rosmarinic acid biosynthesis. Phytochemistry. 2009;70(15-16):1663-79. https://doi.org/10.1016/j.phytochem.2009.05.010 ; PMid:19560175.

33. Al-Attar, A.M. and N.A. Shawush, Physiological investigations on the effect of olive and rosemary leaves extracts in male rats exposed to thioacetamide. Saudi Journal of Biological Sciences, 2014;21(5):473-80. https://doi.org/10.1016/j. sjbs.2014.08.004; PMid:25313283 PMCid:PMC4191576.

34. Zgórka G. and Gtowniak K. Variation of free phenolic acids in medicinal plants belonging to the Lamiaceae family. Journal of Pharmaceutical and Biomedical Analysis, 2001;26(1):79-87. https://doi.org/10.1016/S0731-7085(01)00354-5.

35. Kontogianni VG, Tomic g, Nikolic I, Nerantzaki AA, Sayyad N, Stosic-Grujicic $\mathrm{S}$, et al., Phytochemical profile of Rosmarinus officinalis and Salvia officinalis extracts and correlation to their antioxidant and anti-proliferative activity. Food Chemistry, 2013;136(1):120-9. https://doi.org/10.1016/j.foodchem.2012.07.091 ; PMid:23017402

36. Bradley, P., British Herbal Compendium: A handbook of scientific information on widely used plant drugs (v. 2). British Herbal Medicine Association: Bournemouth (UK), 2006.

37. Do TKT, Hadji-Minaglou F, Antoniotti $S$, and Fernandez X. Authenticity of essential oils. TrAC Trends in Analytical Chemistry, 2015;66:146-57. https://doi org/10.1016/j.trac.2014.10.007.

38. Bousbia N, Abert Vian M, Ferhat MA, Petitcolas E, Meklati BY, and Chemat F, Comparison of two isolation methods for essential oil from rosemary leaves: Hydrodistillation and microwave hydrodiffusion and gravity. Food Chemistry, 2009;114(1):355-62. https://doi.org/10.1016/j.foodchem.2008.09.106.

39. Bayramoglu B, Sahın S, and Sumnu G. Microwave-assisted hydrodistillation of essential oil from Rosemary. in Central theme, technology for all: sharing the knowledge for development. Proceedings of the International Conference of Agricultural Engineering, XXXVII Brazilian Congress of Agricultural Engineering, International Livestock Environment Symposium-ILES VIII, Iguassu Falls City, Brazil, 31st August to 4th September, 2008. 2008: International Commission of Agricultural Engineering (CIGR), Institut fur Landtechnik.

40. Hassiotis CN, Ntana F, Lazari DM, Poulios S, and Vlachonasios KE, Environmental and developmental factors affect essential oil production and quality of Lavandula angustifolia during flowering period. Industrial Crops and Products, 2014;62:359-66. https://doi.org/10.1016/j.indcrop.2014.08.048.

41. Zheljazkov VD, Cantrell CL, Astatkie T, and Jeliazkova E, Distillation time effect on lavender essential oil yield and composition. Journal of oleo science, 2013;62(4):195-9. https://doi.org/10.5650/jos.62.195.

42. Fakhari AR, Salehi P, Heydari R, Ebrahimi SN, and Haddad PR. Hydrodistillation-headspace solvent microextraction, a new method for analysis of the essential oil components of Lavandula angustifolia Mill. Journal of Chromatography A, 2005;1098(1-2):14-8. https://doi.org/10.1016/j.chroma.2005.08.054 ; PMid:16314156.

43. Bajalan, I. and A.G. Pirbalouti, Variation in chemical composition of essential oil of populations of Lavandula $x$ intermedia collected from Western Iran Industrial Crops and Products, 2015;69:344-7. https://doi.org/10.1016/j.indcrop.2015.02.049.

44. Da Porto C, Decorti D, and Kikic I. Flavour compounds of Lavandula angustifolia L. to use in food manufacturing: Comparison of three different extraction 
methods. Food Chemistry, 2009;112(4):1072-8. https://doi.org/10.1016/j.foodchem.2008.07.015.

45. Sienkiewicz M, Głowacka A, Kowalczyk E, Wiktorowska-Owczarek A, JóźwiakBębenista M, and Łysakowska M, The Biological Activities of Cinnamon, Geranium and Lavender Essential Oils. Molecules, 2014;19(12):20929-40. https:// doi.org/10.3390/molecules191220929; PMid:25514231.

46. Ben Salah M, Abderraba M, Tarhouni MR, and Abdelmelek H, Effects of ultraviolet radiation on the kinetics of in vitro percutaneous absorption of lavender oil. International Journal of Pharmaceutics, 2009:382(1-2):33-8. https://doi. org/10.1016/j.jpharm.2009.07.037; PMid:19683042.

47. Ueno-lio T, Shibakura M, Yokota K, Aoe M, Hyoda T, Shinohata R, et al., Lavender essential oil inhalation suppresses allergic airway inflammation and mucous cell hyperplasia in a murine model of asthma. Life Sciences, 2014;108(2):10915. https://doi.org/10.1016/i.lfs.2014.05.018; PMid:24909715.

48. Hassiotis CN, Tarantilis PA, Daferera D, and Polissiou MG. Etherio, a new variety of Lavandula angustifolia with improved essential oil production and composition from natural selected genotypes growing in Greece. Industrial Crops and Products, 2010;32(2):77-82. https://doi.org/10.1016/j.indcrop.2010.03.004.

49. Martucci JF Gende LB, Neira LM, and Ruseckaite, Oregano and lavender essential oils as antioxidant and antimicrobial additives of biogenic gelatin films Industrial Crops and Products, 2015;71:205-13. https://doi.org/10.1016/j.indcrop.2015.03.079

50. Mostefa MB, Kabouche A, Abaza I, Aburjai T, Touzani R, and Kabouche Z. Chemotypes investigation of Lavandula essential oils growing at different North African soils. Journal of Materials and Environmental Science, 2014;5(6):1896 $-901$

51. Wang W, Wu N, Zu YG, and Fu YJ, Antioxidative activity of Rosmarinus officinalis $\mathrm{L}$. essential oil compared to its main components. Food Chemistry, 2008;108(3):1019-22. https://doi.org/10.1016/j.foodchem.2007.11.046; PMid:26065766.

52. Behrendorff JB, CE Vickers, Chrysanthopoulos P, and Nielsen LK. 2, 2-Diphenyl1-picrylhydrazyl as a screening tool for recombinant monoterpene biosynthesis. Microbial cell factories, 2013:12(1):1. https://doi.org/10.1186/1475-2859-12-76; PMid:23968454 PMCid:PMC3847554

53. Mitić-Ćulafić D, Žegura B, Nikolić B, Vuković-Gačić B, Knežević-Vukčević J, and Filipič M. Protective effect of linalool, myrcene and eucalyptol against t-butyl hydroperoxide induced genotoxicity in bacteria and cultured human cells. Food and Chemical Toxicology, 2009;47(1):260-6. https://doi.org/10.1016/j. fct.2008.11.015; PMid:19049815.

54. Ciftci O, Ozdemir I, Tanyildizi S, Yildiz S, and Oguzturk H. Antioxidative effects of curcumin, $\beta$-myrcene and 1, 8-cineole against 2, 3, 7, 8-tetrachlorodibenzo$\mathrm{p}$-dioxin-induced oxidative stress in rats liver. Toxicology and Industrial Health 2011:27(5):447-53. https://doi.org/10.1177/0748233710388452; PMid:21245202.

55. Carrasco A, Ortiz-Ruiz V, Martinez-Gutierrez R, Tomas V, and Tudela J. Lavandula stoechas essential oil from Spain: Aromatic profile determined by gas chromatography-mass spectrometry, antioxidant and lipoxygenase inhibitory bioactivities. Industrial Crops and Products, 2015;73:16-27. https://doi.org/10.1016/j. indcrop.2015.03.088.

56. Dawidowicz AL and Olszowy M. Does antioxidant properties of the main component of essential oil reflect its antioxidant properties? The comparison of antioxidant properties of essential oils and their main components. Natural product research, 2014;28(22):1952-63. https://doi.org/10.1080/14786419.2014.918121 PMid:24849850

57. Hussain Al, Anwar F, Sherazi STH, and Przybylski R, Chemical composition, antioxidant and antimicrobial activities of basil (Ocimum basilicum) essential oils depends on seasonal variations. Food Chemistry, 2008;108(3):986-95. https:// doi.org/10.1016/j.foodchem.2007.12.010; PMid:26065762.

58. Djenane $D$, Aïder $M$, Yangüela J, Idir L, Gómez $D$, and Roncalés P. Antioxidant and antibacterial effects of Lavandula and Mentha essential oils in minced beef inoculated with $\mathrm{E}$. coli $\mathrm{O} 157: \mathrm{H7}$ and S. aureus during storage at abuse refrigeration temperature. Meat Science. 2012;92(4):667-74. https://doi.org/10.1016/i. meatsci.2012.06.019; PMid:22789458

59. Höferl M, Stoilova I, Schmidt E, Wanner J, Jirovetz L, Trifonova D, et al., Chemical composition and antioxidant properties of juniper berry (Juniperus communis L) essential oil. Action of the essential oil on the antioxidant protection of Saccharomyces cerevisiae model organism. Antioxidants, 2014;3(1):81-98 https://doi.org/10.3390/antiox3010081; PMid:26784665 PMCid:PMC4665443.

60. Somani R, Kasture $S$, and Singhai AK, Antidiabetic potential of Butea monosperma in rats. Fitoterapia, 2006;77(2):86-90. https://doi.org/10.1016/j.fitote.2005.11.003: PMid:16376023.

61. González-Trujano ME, Pe-a El, Martínez AL, Moreno J, Guevara-Fefer P, DécigaCampos M. et al., Evaluation of the antinociceptive effect of Rosmarinus of ficinalis $\mathrm{L}$. using three different experimental models in rodents. Journal of ethnopharmacology, 2007;111(3):476-82. https://doi.org/10.1016/j.jep.2006.12.011 ; PMid:17223299,

62. Pérez-Sánchez AE, Barrajón-Catalán, Caturla N, Castillo J, Benavente-García $\mathrm{O}$, Alcaraz $\mathrm{M}$, et al., Protective effects of citrus and rosemary extracts on UVinduced damage in skin cell model and human volunteers. Journal of Photochemistry and Photobiology B: Biology. 2014;136;12-8. https://doi.org/10.1016/i. jphotobiol.2014.04.007; PMid:24815058.

\footnotetext{
SUMMARY
Monographs designed for Rosmarinus officinalis (Linn.) and Lavandula angustifolia (Linn.) provided a proof that
these cultivated species at the botanical garden of Beirut Arab University fulfill the international standards specified
by the BP 2013 and WHO.
The antioxidant potential of their essential oils has been demonstrated.
Rosemary was proven to have antidiabetic potential.
ABOUT AUTHORS
Mariam Koleilat: Is a teaching assistant at the Faculty of Pharmacy, Beirut Arab University (BAU) where she graduated in Bachelor
of Pharmaceutical Sciences and Master of Pharmacognosy and Medicinal Plants. Her Masters research focused on designing
monographs for Rosmarinus officinalis (Linn.) and Lavandula angustifolia (Linn.) as well as evaluating the antioxidant potentials of
their essential oils and the antidiabetic effect of Rosemary
Dr. Karim M. Raafat: Has completed his PhD from German University in Cairo, New Cairo, Egypt, under the channel system
and joint supervision scheme between The German University in Cairo (GUC) and Johann Wolfgang Goethe-University Frankfurt,
Germany and postdoctoral studies from Beirut Arab University (BAU) and German University in Cairo. He is a visiting Scientist of
Johann Wolfgang Goethe-University, Frankfurt, Germany. He is the Head of Phytochemistry Research Team and Junior Research
Team, BAU, Lebanon. He has published more than fifty books, patent, and peer reviewed journal articles and presentations in
scientific conferences. He has been honored with several national and international awards in the scientific field and public service
} 


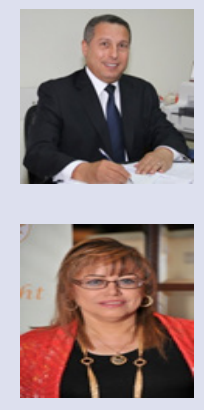

Prof. Abdalla El-Lakany: Is currently the Dean of Faculty of Pharmacy, Beirut Arab University. Dr. El-Lakany has over 25 years of experience in teaching Phytochemistry, Pharmacognosy, and Medicinal Plants, and supervision of PhD, Masters and Pharm.D. theses. He is specialized in chemistry of natural products, with a special interest in diterpenoids, alkaloids and flavonoids. He has attended many national and international conferences and supervising more than 20 Master, Pharm.D and PhD Theses. Currently, he has a research project about alkaloids and their biological testing. He has published more than 55 scientific articles in highimpact journals.

Prof. Maha Aboul-Ela: Is the Head of Pharmaceutical Sciences Department, Faculty of Pharmacy, Beirut Arab University. Dr. Aboul-Ela has 30 years experience in teaching (under and post graduates courses) and research in Pharmacognosy and Phytochemistry and 7 years experience in the field of QA in Higher education. Distinguishable Peer Reviewer at Egyptian National Organization for QA and accreditation. She has published more than 50 research articles in national and international scientific journals in the field of specialization. Attending many national and international conferences. Supervising more than 14 Master, Pharm.D and PhDTheses. She had PhD mission to West Germany for completion of practical studies and postdoctoral mission to School of Pharmacy, University of London, UK. She has Membership in the American Society of Pharmacognosy and the Egyptian Pharmaceutical Society.

Cite this Article: Koleilat M, Raafat K, El-Lakany A, Aboul-Ela M. Designing monographs for Rosmarinus officinalis L. and Lavandula angustifolia L.: Two Lebanese species with significant medicinal potentials. Pharmacogn J. 2017;9(4): 452-74. 